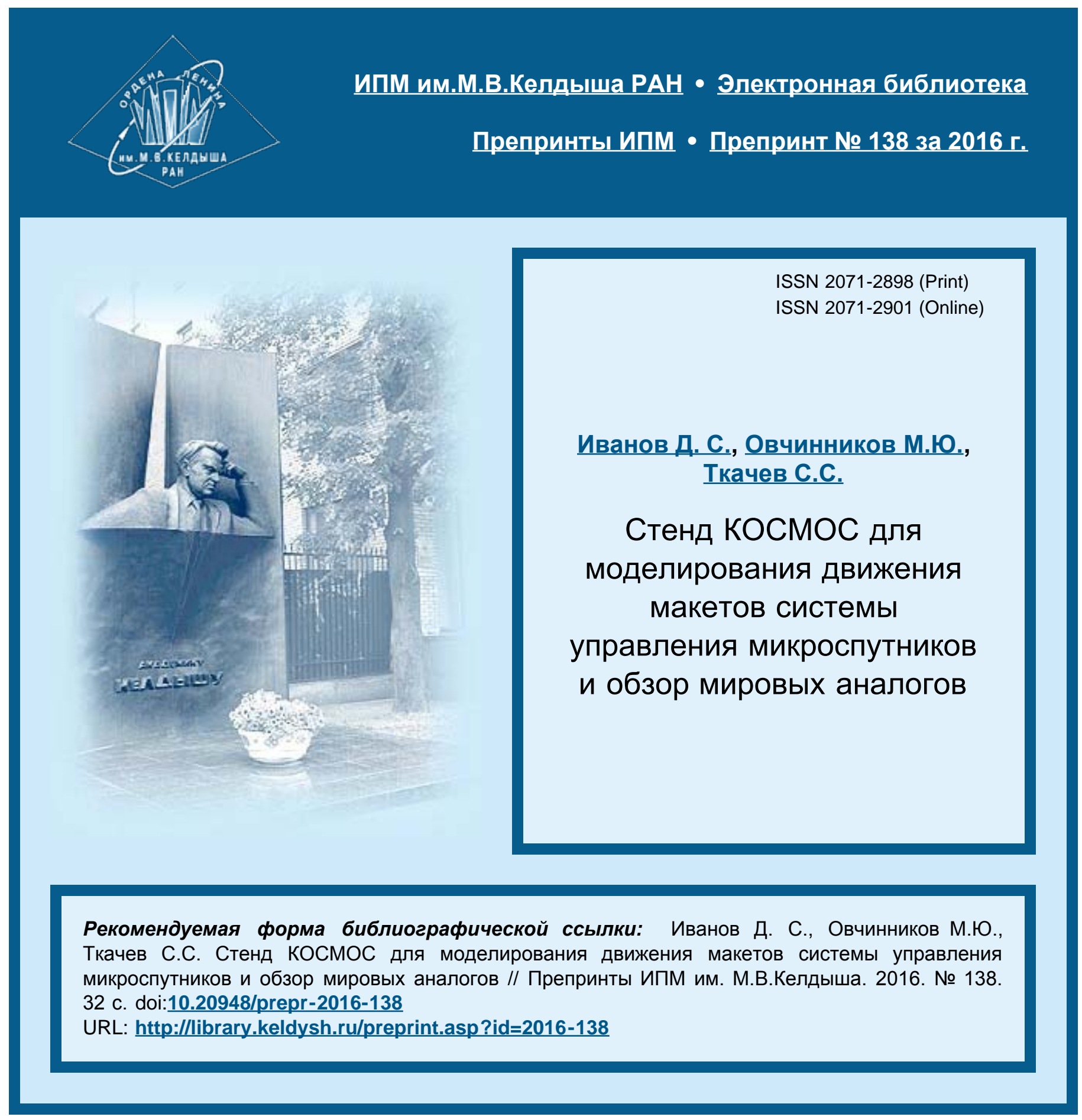




$$
\begin{gathered}
\text { О р д е н а Л е н и н } \\
\text { ИНСТИТУТ ПРИКЛАДНОЙ МАТЕМАТИКИ } \\
\text { имени М.В. Келдыша } \\
\text { Р о с и й с к й а к а д м и и н у к }
\end{gathered}
$$

Д.С. Иванов, М.Ю. Овчинников, С.С. Ткачев

\section{Стенд КОСМОС}

для моделирования движения макетов системы управления микроспутников и обзор мировых аналогов 


\section{Иванов Д.С., Овчинников М.Ю., Ткачев С.С.}

Стенд КОСМОС для моделирования движения макетов системы управления микроспутников и обзор мировых аналогов

В работе представлено описание стенда КОСМОС для моделирования движения системы управления микроспутников, установленного в ИПМ им. М.В.Келдыша. Стенд состоит из аэродинамического стола и макетов систем управления движением микроспутников. Благодаря воздушной подушке между поверхностью стола и дисками, на которых установлены макеты, становится возможным свободное движение с тремя степенями свободы: две поступательные и одна вращательная. Проведен обзор мировых аналогов стенда, который выявил его преимущества и недостатки.

Ключевые слова: микроспутник, аэродинамический стенд, управление движением

Ivanov D.S., Ovchinnikov M.Yu., Tkachev S.S.

Test-Bench COSMOS for Microsatellite Control System Mock-Ups Modeling and Survey

A description of the KIAM laboratory facility COSMOS is presented. The facility allows to simulate microsatellite free and controllable planar motion due to aerodynamic cushion. The overview of the similar facilities is provided in the paper.

Key words: microsatellite, air test-bed, motion control

Работа выполнена при поддержке Министерства образования и науки Российской Федерации (соглашение № 14.607.21.0144, уникальный идентификатор ПНИЭР - RFMEFI60716Х0144). 


\section{Введение}

Наземное тестирование системы управления спутниками на специальных стендах позволяет отладить её работу, подтвердить работоспособность алгоритмов и оценить их точность и быстродействие. Кроме того, демонстрация реализованных в "железе" новых подходов к управлению и определению движения вызывает большее, по сравнению с математическим моделированием работы алгоритмов, доверие как учёных, так и инженеров. Этим объясняется повсеместное распространение лабораторий, позволяющих моделировать движение спутников в приближенных к орбитальным условиях.

Растущая популярность малых, микро- и наноспутников привела к идеям кластерного запуска, что приводит к необходимости управления относительным движением спутников в группе. В зарубежных университетах и исследовательских институтах стали возникать стенды, позволяющие имитировать относительное движение макетов систем управления таких спутников. Стенды состоят из плоской поверхности и макетов со специальной системой, создающей воздушную прослойку между ножками макета и поверхностью стола. Благодаря этому макеты двигаются по ней практически без трения, что позволяет имитировать свободное орбитальное движение. Однако для создания воздушной подушки требуется наличие баллонов со сжатым газом на самом макете, что накладывает требования к безопасности, а запас газа ограничивает время проведения эксперимента. Поэтому в ИПМ им. М.В. Келдыша был создан стенд на основе аэродинамического стола. Воздух, нагнетаемый в герметичную полость под столом, проходит через отверстия в его верхней горизонтальной поверхности создает воздушную прослойку между столом и плоским диском, на который устанавливается макет. Это облегчает и упрощает конструкцию макета, а также снимает ограничения на продолжительность экспериментов.

В настоящей работе приводится описание созданного стенда, описаны особенности его работы. Приводится обзор технических решений для зарубежных аналогов, что позволяет выявить преимущества и недостатки стенда в ИПМ и наметить направления его усовершенствования.

\section{1 Лабораторный стенд в ИПМ}

В состав стенда, названного КОСМОС (КОмплекС для МОделирования движения Спутников), входит аэродинамический стол, промышленный вентилятор с блоком управления и системой трубопроводов, а также макеты системы управления микроспутников. Аэродинамический стол представляет собой плоское металлическое основание с отверстиями, через которые поступает воздух, нагнетаемый промышленным вентилятором по системе воздуховодов. Таким образом создается воздушная подушка между поверхностью стола и дис- 
кообразной платформой, на которую устанавливается макет системы управления. Общий вид стенда представлен на рис. 1. Промо-ролик про стенд можно просмотреть при нажатии на рис.1 или пройти по адресу: https://www.youtube.com/watch?v=jQR3luT75TY.

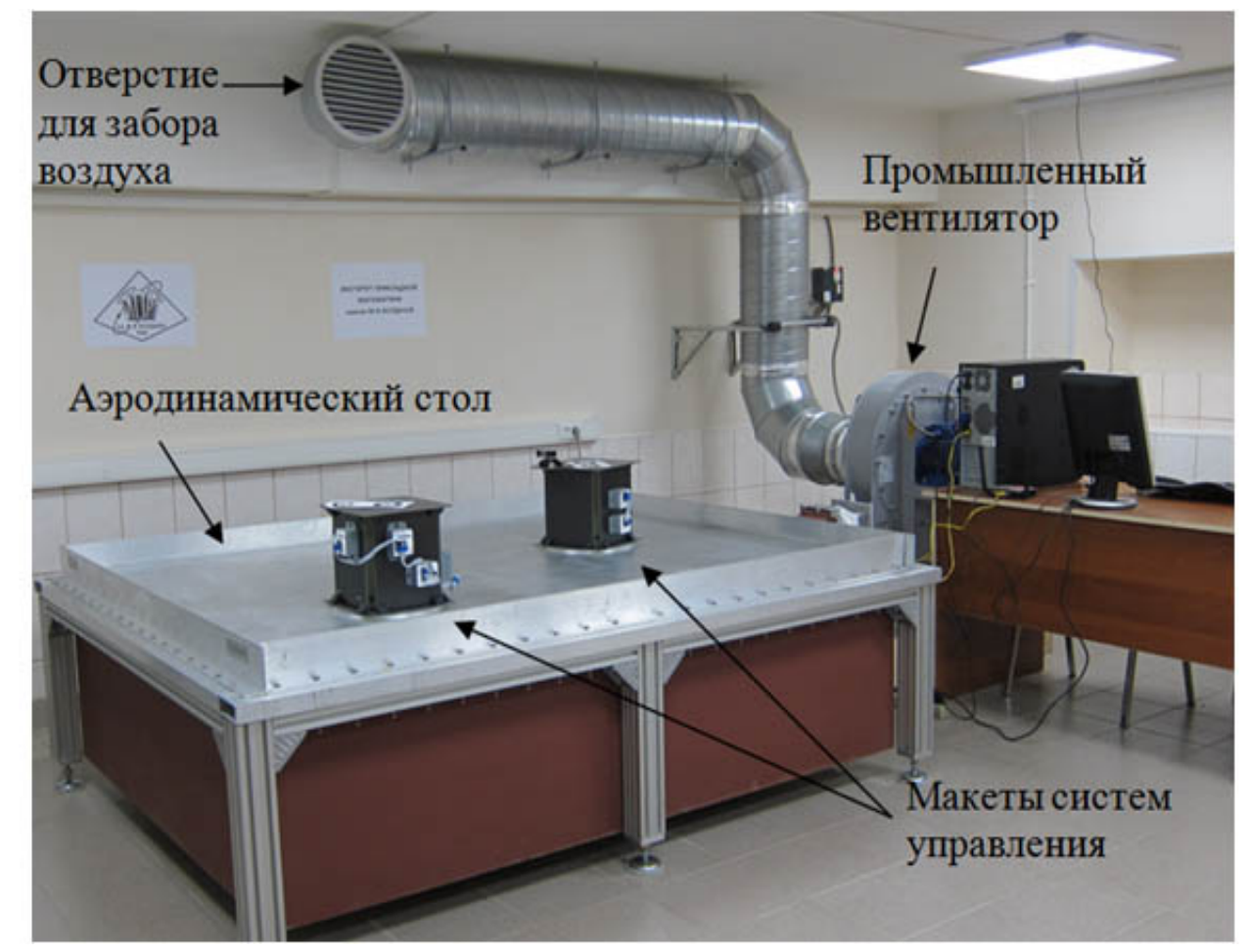

( 11 Рис.1. Стенд КОСМОС в ИПМ им. М.В. Келдыша

\section{1 Аэродинамический стол}

Рабочая поверхность аэродинамического стола выполнена из двух алюминиевых пластин толщиной 1 см, соединенных “в стык” между собой. С нижней стороны поверхность закреплена на специальном каркасе, препятствующем провисанию пластин под силой собственной тяжести или их выгибанию под действием избыточного давления воздуха снизу, что обеспечивает плоскостность стола на уровне 2 мм по всей поверхности. Размер рабочей поверхности стола составляет $198 \times 148$ см.

На поверхности стола выполнена сетка из отверстий с диаметром 1 мм с шагом 20 мм (рис.2). Расстояние между отверстиями выбрано исходя из расчёта для создания воздушной подушки для макетов массой до 6 кг при максимальных оборотах нагнетающего вентилятора.

Основание аэродинамического стола установлено на шести опорах, регулируемых по высоте в заданных пределах и являющихся частью несущей конструкции (рис.3). Благодаря регулировке удается выровнять средний уровень стола с миллиметровой точностью. 


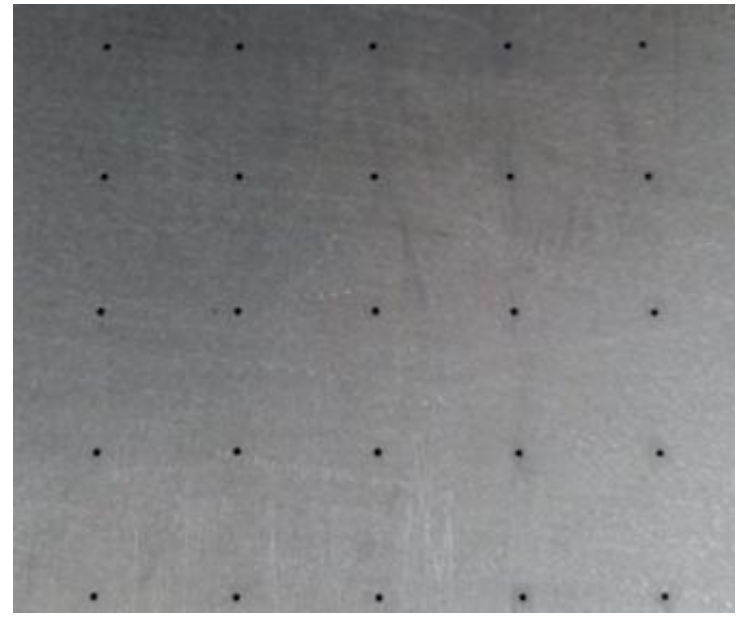

Рис.2. Отверстия на поверхности стола

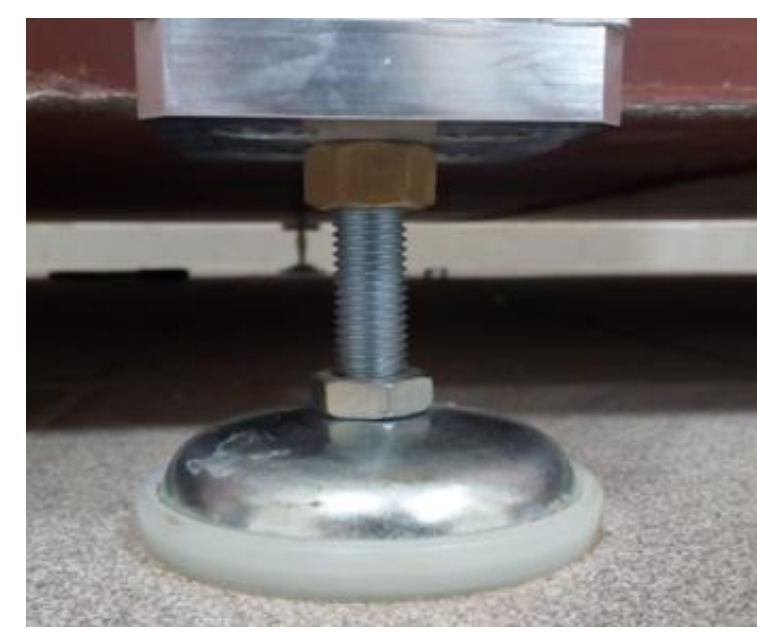

Рис. 3. Регулируемая опора стола

К нижней части поверхности стола крепится камера статического давления, в которую с помощью промышленного вентилятора нагнетается воздух. Она является частью системы воздуховодов и служит для создания избыточного давления под поверхностью стола. Рабочая поверхность стола соединяется с камерой статического давления по средствам переходного фланца. Фланец содержит уплотнение, препятствующее утечке воздуха. Для предотвращения передачи вибраций на стол выходящий из промышленного вентилятора воздух подается в гибкий воздуховод, который потом соединяется с воздуховодом переменного сечения, как изображено на рис. 4.

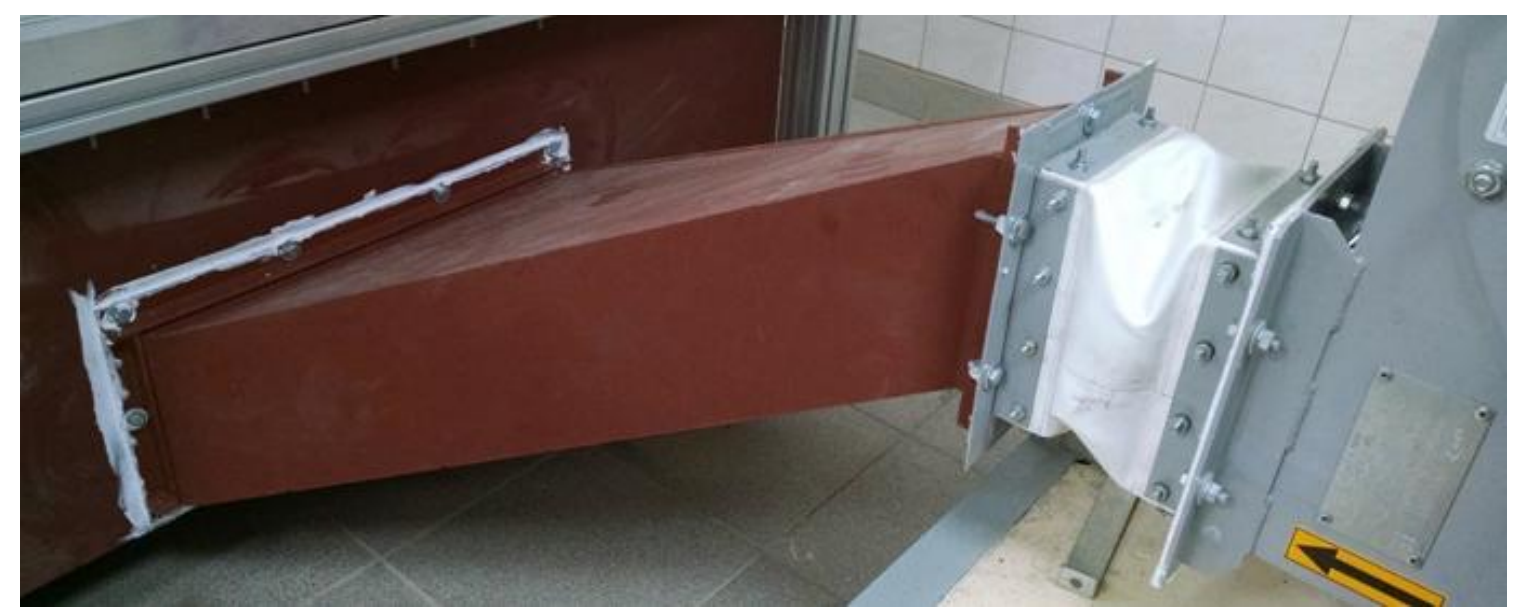

Рис. 4. Система воздуховодов на выходе из промышленного вентилятора

\section{2 Промышленный вентилятор}

Для нагнетания воздуха используется промышленный вентилятор, изображенный на рис. 5. Он установлен на специальном фундаменте через демпферы для снижения вибрации. Частота вращения вентилятора плавно регулируется с помощью блока управления в диапазоне от 20 до 50 Гц, что позволяет плавно изменять грузоподъемность воздушной подушки на поверхности стола. Для то- 
го чтобы избежать появления горизонтальных потоков воздуха в лаборатории, приводящих к дополнительным возмущениям на плоское движение макетов, забор воздуха вентилятором производится над столом (см. рис. 1). Таким образом, выходящий из отверстий на поверхности стола воздух всасывается в вентилятор сверху стола.
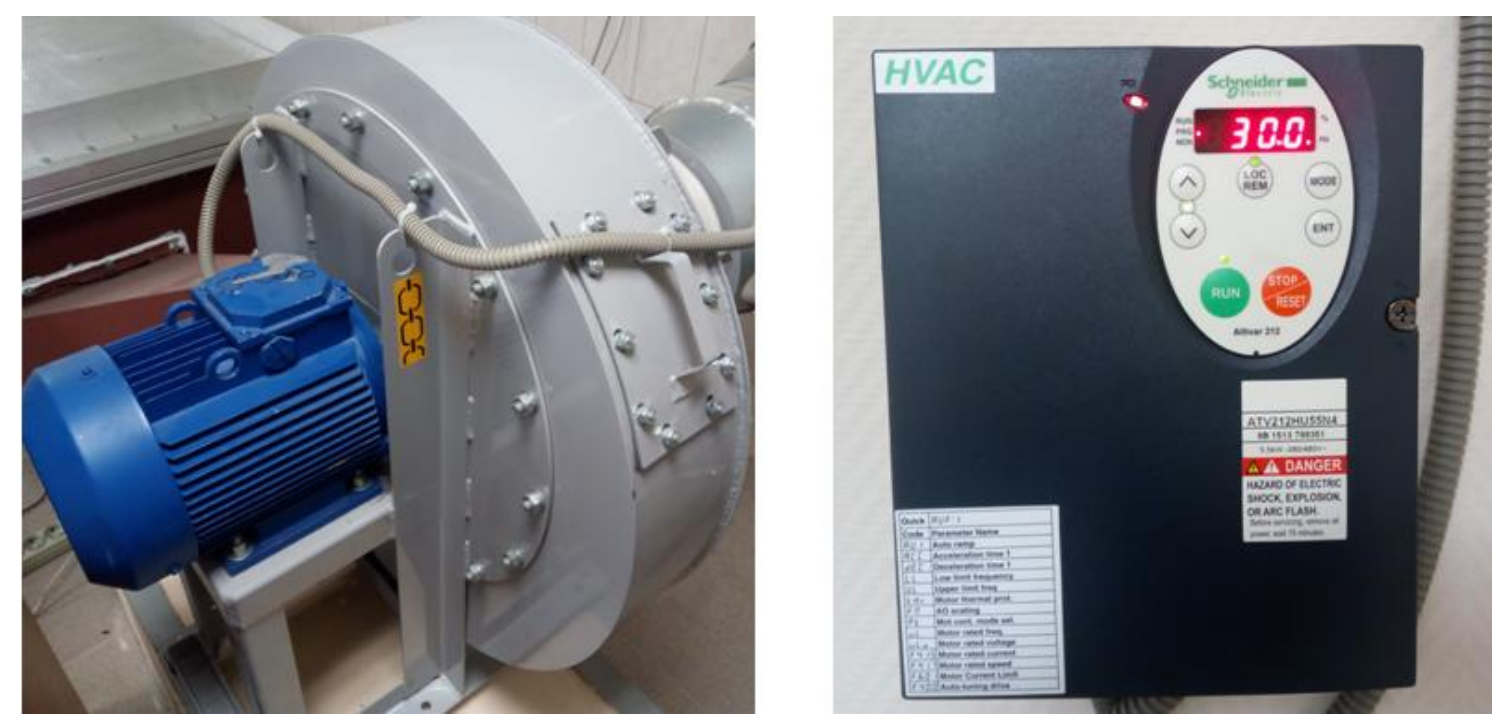

Рис. 5. Промышленный вентилятор и блок управления

\section{3 Макеты систем управления}

Макеты систем управления крепятся к специальным плоским алюминиевым дискам диаметром 30 см и толщиной 1 см (рис. 6). С одной стороны диск плоский для обеспечения создания воздушной подушки, а с другой находятся отверстия, через которые основание макета крепится к диску.

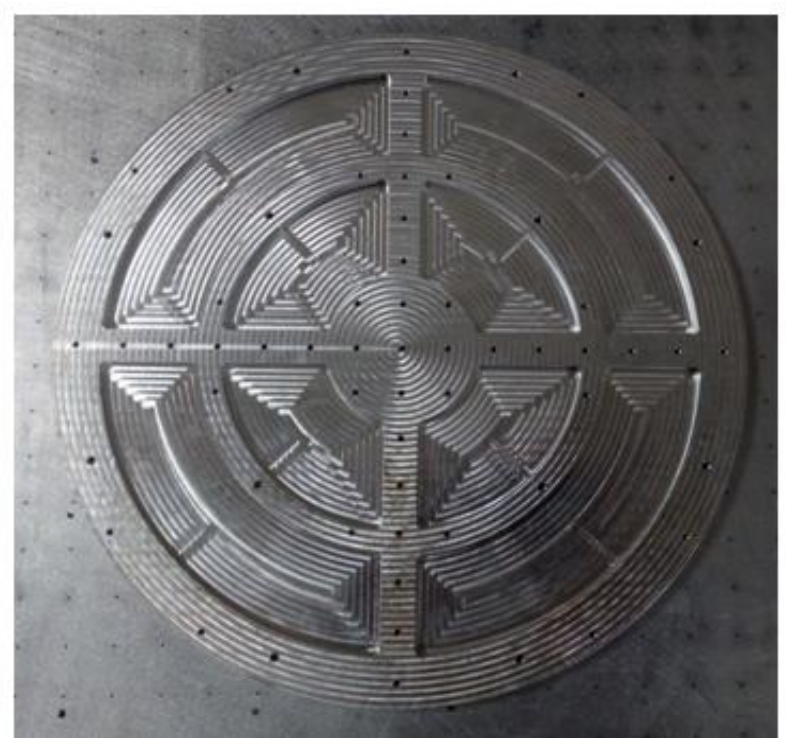

Рис. 6. Диск на поверхности стола (верхняя сторона) 
Корпус макетов систем управления сделан в форме восьмиугольной призмы высотой 40 см. Пластины, из которых сделан корпус, вырезаны из сендвич-панели, состоящей из двух алюминиевых пластин и пластикового наполнения между ними. В пластинах выполнена сетка из отверстий для крепления элементов системы управления, которые могут быть установлены как снаружи макета, так и внутри, как показано на рис. 7.
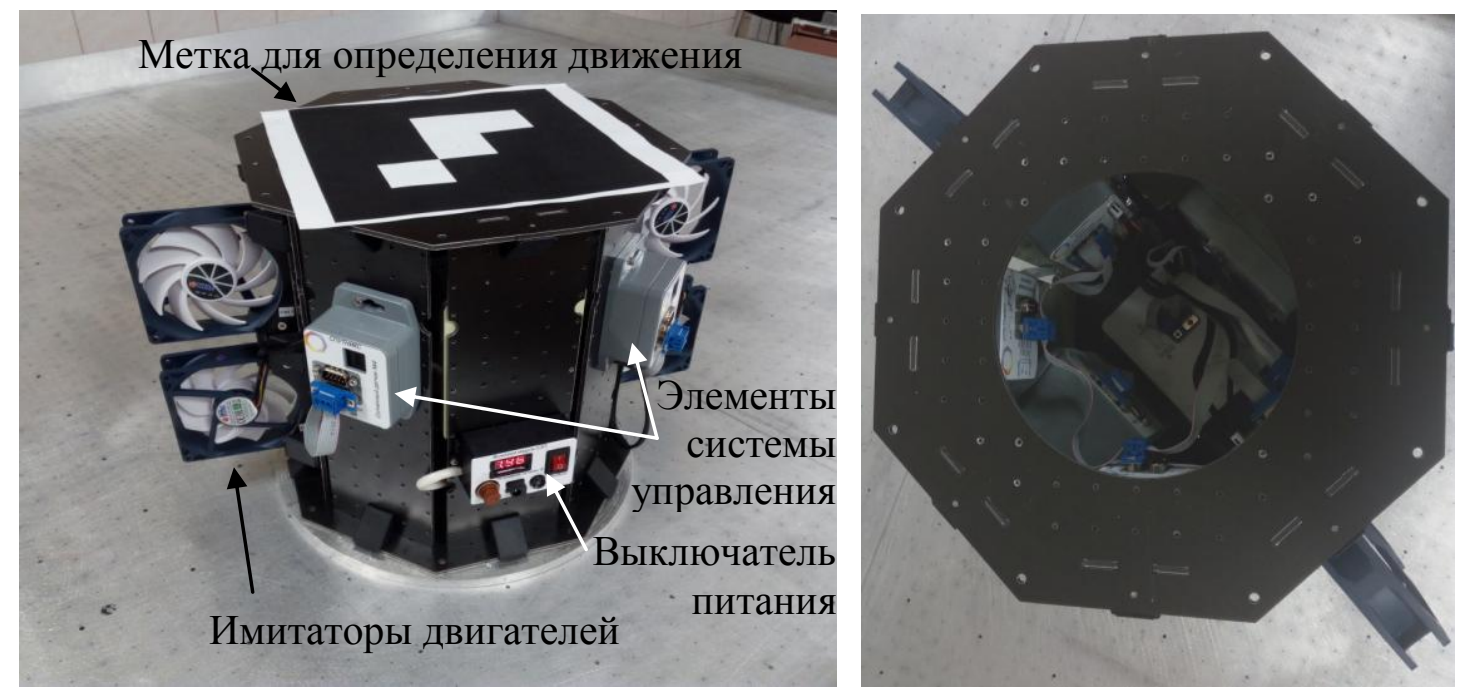

Рис. 7. Макет системы управления внешний вид и внутренее наполнение

Система управления макетами строится на элементной основе конструктора Орбикрафт, разработанной компанией Спутникс [1]. Функциональный макет системы управления содержит:

- бортовой компьютер Raspberry PI B+;

- систему энергопитания, включающую в себя аккумулятор и блок управления питанием;

- систему передачи команд на управляющие элементы и сбора телементрии с датчиков;

- датчики для определения движения: набор солнечных датчиков, магнитометр, датчик угловой скорости, акселерометр;

- управяющие актюаторы: одноосный двгатель-маховик, 4 вентилятора, имитирующих двигатели тяги;

- бортовую веб-камеру, которая может быть использована для определения относительного движения макетов;

- Wi-Fi-канал связи.

На верхней крышке каждого макета закреплена специальная контрастная метка в виде QR-кода. Над столом установлена веб-камера, по обработке снимков которой на стационарном компьютере определяется положение и ориентация макетов на столе, а также их линейная и угловая скорость [2]. Эти измерения отсылаются по Wi-Fi на бортовой компьютер макетов, и по ним рассчитываются управляющие команды на актюаторы. Эта система может быть использована также как система независимого определения движения макетов. 


\section{2 Обзор аналогов стенда}

Для выявления особенностей разработанного стенда был проведен обзор возможных реализаций аэродинамического стола и способов определения движения на нем. Также обзор выявил задачи, которые решаются или могут быть решены с помощью подобных стендов.

\section{1 Возможные реализации аэродинамического стола}

Существуют два подхода для создания обезвешивающей силы: с помощью избыточного давления воздуха, выходящего через специальные отверстия на поверхности стола, и с помощью установленного на макете устройства для создания под ним автономной воздушной подушки с использованием установленных на макете баллонов со сжатым воздухом. Ниже рассматривается подробно каждое из этих решений.

\section{Использование автономной воздушной подушки}

В случае использования автономной воздушной подушки воздух нагнетается из баллонов, установленных на борту макета, и выпускается через специальные отверстия на опорах макета (рис. 8). Для обеспечения длительной непрерывной работы (30-45 минут) давление воздуха в баках должно быть достаточно большим (в некоторых реализациях оно достигает 300 бар [3]), но, как правило, рабочее давление находится в пределах между 1 [4] и 12 [3] бар, и поэтому время активной работы обычно невелико.

Схема опоры макета изображена на рис. 8 (справа). Через канал подачи газа воздух проникает в пористую среду ножки и на выходе из неё создаёт газовую прослойку между ножкой и гладкой горизонтальной поверхностью стола. Ножки макета также способны двигаться, так как стержень ножки снабжен “суставом”, благодаря которому ножка может поворачиваться. Это необходимо для того, чтобы обеспечить касание ножки всей своей поверхностью стола, в случае если он имеет небольшие искривления.
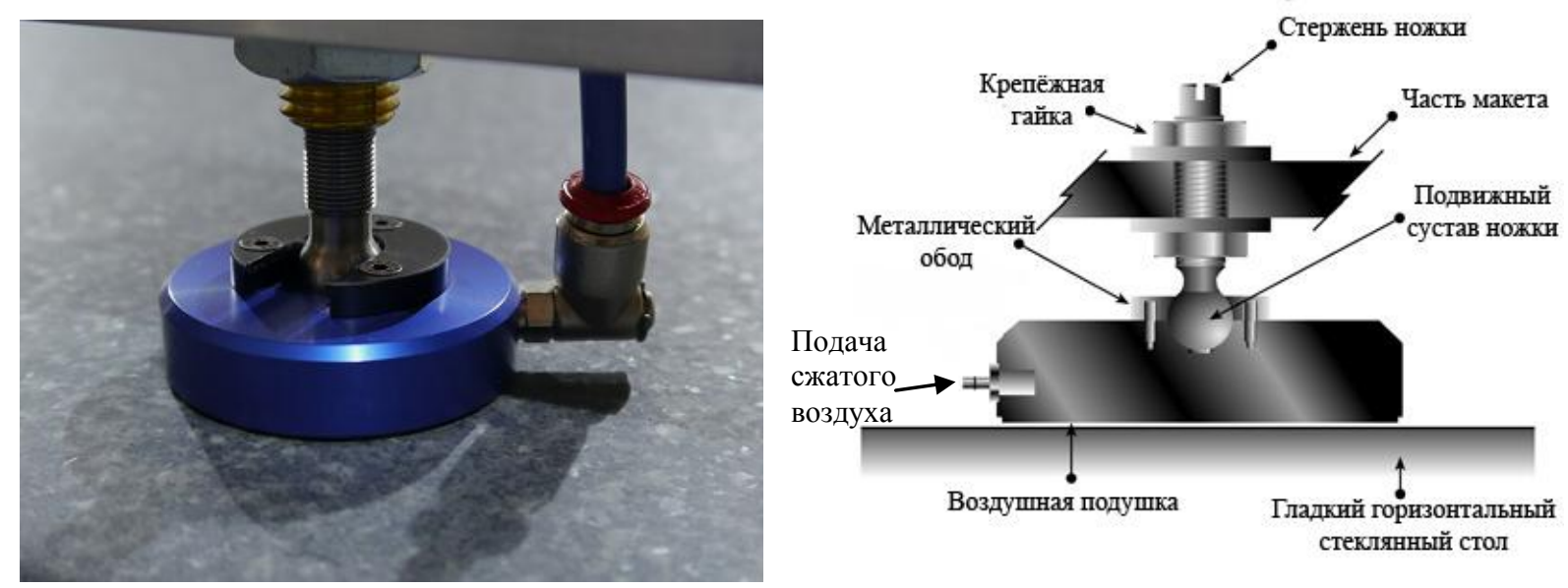

Рис. 8 Опора макета и её схема 
Толщина воздушного слоя между столом и макетом, как правило, не превышает долей миллиметра, что выливается в высокие требования к гладкости поверхности стола. При этом в качестве материала рабочей поверхности необходимо выбирать те, которые не подвержены значительным деформациям под действием температуры, силы тяжести, других факторов.

Популярным решением являются гранитные поверхности (рис. 9), например, подобный стол размером 2.2 на 1.8 метра используется в Техническом университет Афин [5], 4 на 2.5 метра - в Институте космических систем Немецкого центра авиации и космонавтики (DLR) [3], 2 на 3 метра - в Центре космических исследований Польской академии наук [6]. Недостатками подобных столов является их слабая масштабируемость (плита должна по возможности быть цельной), а также сложность монтажа и большой вес конструкции.

Другим возможным решением является использование стеклянной поверхности (обычно это стекло толщиной до 10 мм), подобные столы установлены, например, в Центре прикладных космических технологий и микрогравитации [7] и в Токийском технологическом институте [8]. Размер рабочей поверхности таких столов также ограничен возможностями по изготовлению и, как правило, меньше $4 \mathrm{M}^{2}$.

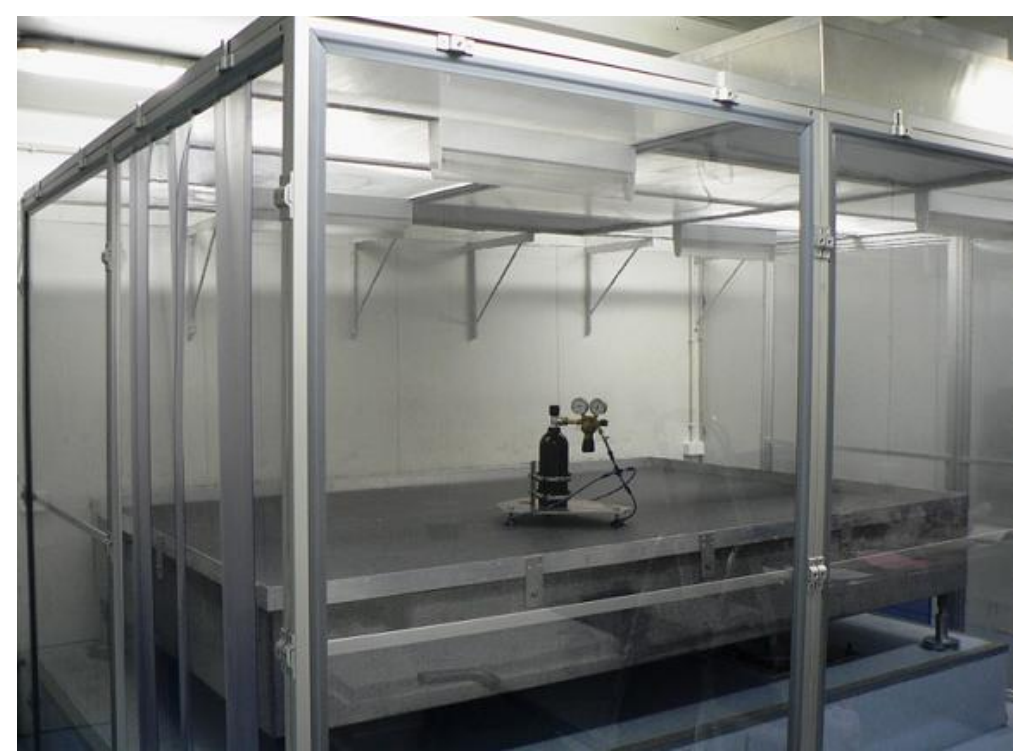

Рис. 9. Аэродинамический стол с гранитной плитой

Наконец, изготовление рабочей поверхности возможно с использованием эпоксидной смолы. В этом случае размеры поверхности ограничены лишь размером помещения, в котором они создаются. Подобная поверхность используется, например, в Массачусетском технологическом институте [9]. Она имеет форму восьмиугольника диаметром 5.1 м. Такой тип поверхности прост в монтаже и значительно дешевле гранита и стекла, но качество поверхности в этом случае заметно хуже, что требует большего давления в баках, установленных на макетах (рис. 10). Например, в [10] приведена форма поверхности стола, уста- 
новленного в Технологическом институте Джорджии (США), разница высот достигает 2.5 мм . Давление в баках при этом достигает 130 бар.

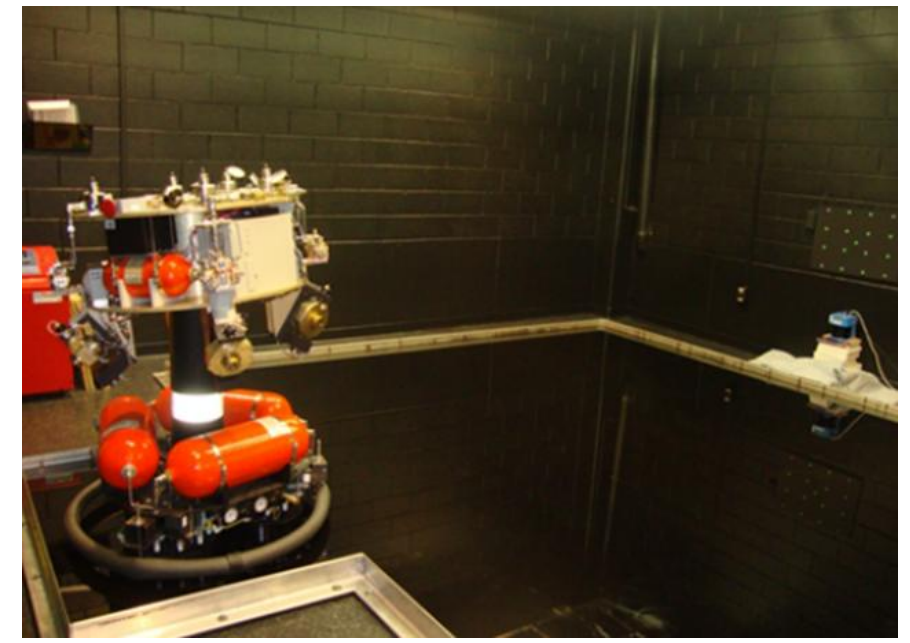

Рис. 10. Стол из эпоксидной смолы (Технологический институт Джорджии)

В любом случае, вне зависимости от типа поверхности, на борту макета устанавливается дополнительное оборудование для создания воздушной подушки, обеспечивающей скольжение с минимальным трением. Это требует наличия не только баков с высоким давлением на борту макета, но и системы их заправки в лаборатории, что значительно усложняет эксплуатацию системы, а в некоторых и совсем исключает ее полностью (например, в учебных лабораториях, где правилами техники безопасности может быть запрещено использование подобного оборудования). В этом случае решением может быть использование аэродинамического стола, в котором воздушная подушка создается непосредственно самим столом.

\section{Аэродинамический стол с воздушной подушкой}

В отличие от приведенной выше схемы в этом случае воздух подается снизу, по аналогии со столом для аэрохоккея. Подобный стол создан по заказу ИПМ им.М.В.Келдыша РАН российской компанией ООО «Спутникс» и описан в первом разделе настоящей работы. Под столом имеется камера (рис. 1), куда промышленным вентилятором нагнетается воздух под избыточным давлением. Воздух выходит через отверстия в горизонтальной поверхности стола, создавая таким образом обезвешивающую силу. Аналогичный стол находится в Лаборатории распределенных космических систем университета Технион в Израиле (рис. 11). Этот стол состоит из 9 пластин размером $1 \times 1 \mathrm{~m}^{2}$ с отверстиями, скрепленных друг с другом [11]. 


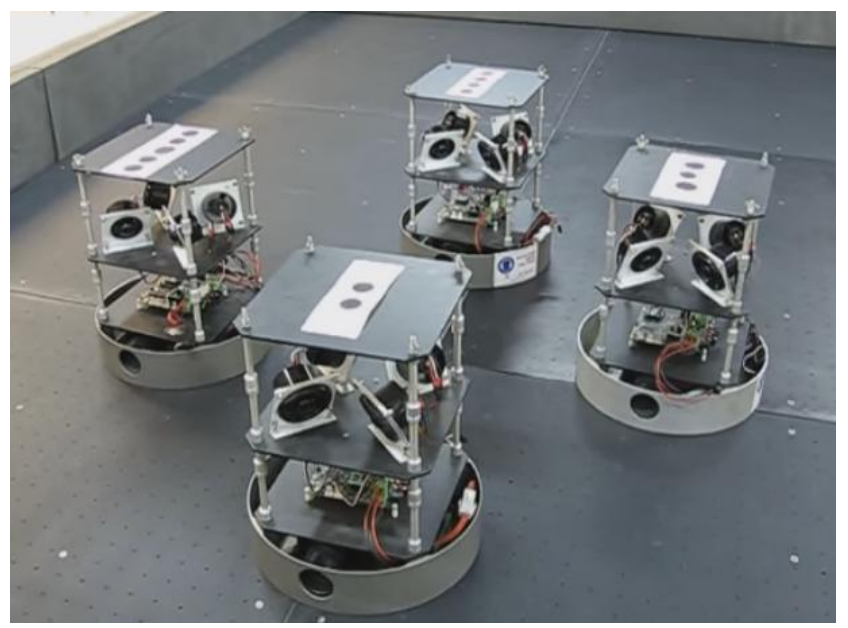

Рис. 11. Аэродинамический стол с макетами в Лаборатории распределенных космических систем

Подобное решение, с одной стороны, позволяет существенно облегчить и упростить конструкцию макета за счет исключения из ее состава системы создания воздушной подушки, но, с другой - требует установки специальной системы для нагнетания воздуха.

\section{2 Методы определения движения на аэродинамическом столе}

Для управления макетами системы управления спутников необходимо знать текущий вектор состояния объекта. Для макетов на аэродинамическом столе - это положение и скорость центра масс макета, угол поворота и угловая скорость относительно его центра масс.

Для определения движения макетов могут использоваться как бортовые датчики, так и внешние измерители. В качестве бортовых датчиков, как правило, используются те же датчики, что и на реальных аппаратах. Внешние измерители же могут использоваться для имитации системы глобального навигационного позиционирования, а также в качестве системы независимых измерений, которая необходима для сравнения реального движения макетов с оценкой этого движения с помощью бортовых датчиков.

Для определения вектора состояния макетов на столе используется широкий набор измерительных средств и методов обработки измерений. Большую популярность получили средства определения движения с помощью обработки видеоизображения. Видеокамера при этом может как располагаться на самом подвижном макете и при этом работать как звездный датчик или датчик для определения относительного расстояния при стыковке, так и быть установлена над столом и представлять собой систему независимых измерений. Другим часто используемым средством для определения движения на аэродинамическом столе является блок инерциальных датчиков, который представляет собой набор из двухосного акселерометра и одноосного датчика угловой скорости. 
Обработка видеоизображения

\section{Звездный датчик}

Определение движения макетов с помощью аналога звездного датчика проводилось на стенде в Центре космических технологий и микрогравитации (ZARM) в г. Бремене. Стенд состоит из гладкого стеклянного стола, двух макетов, движущихся по поверхности стола без трения благодаря воздушной подушке, имитатора Солнца и имитатора звездного неба - набора светодиодов, установленных на потолке над стеклянным столом (рис. 12) [12,13].

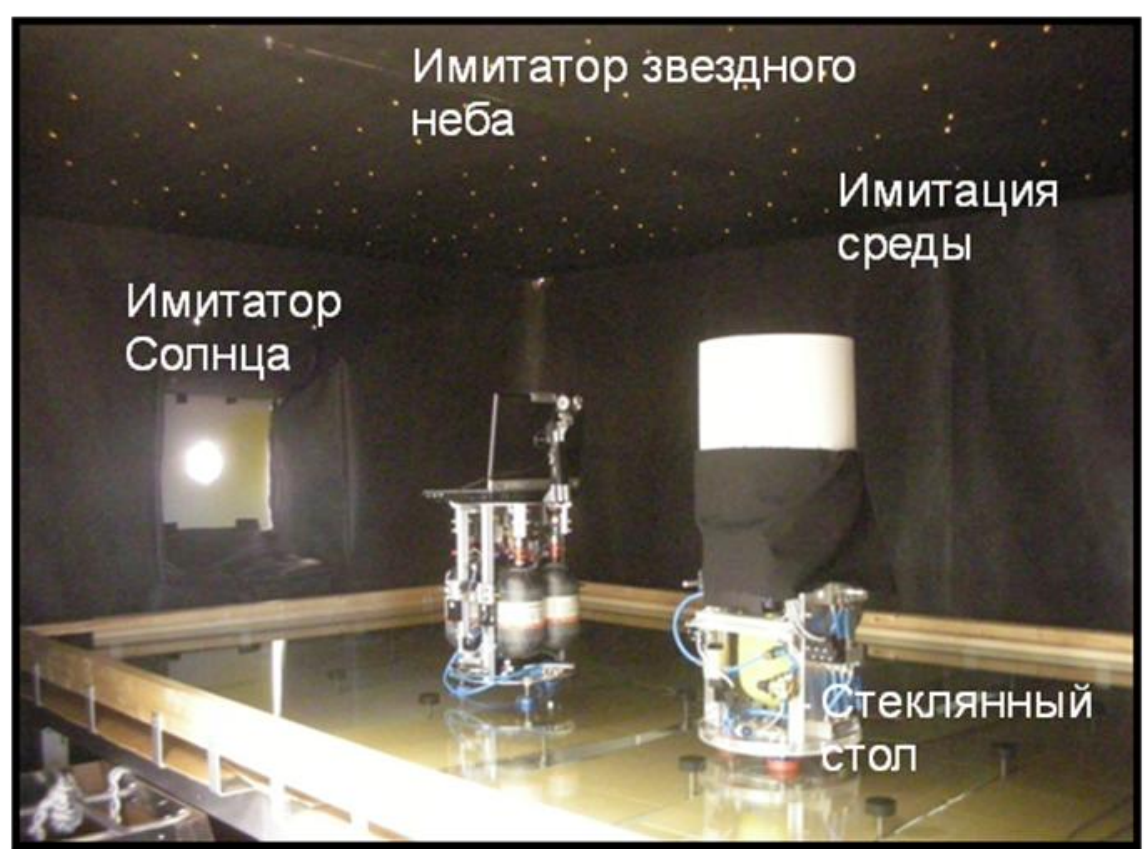

Рис. 12. Общий вид стенда в ZARM

На верхней части макета была установлена веб-камера, оптическая ось которой направлена вертикально вверх на потолок с имитацией звездного неба, как показано на рис.13. Положение 140 "звезд" на потолке считается известным и занесено в каталог. Веб-камера делала снимки участков "звездного неба", которые обрабатывались на бортовом компьютере. Блок-схема алгоритма с основными этапами представлена на рис. 14. 


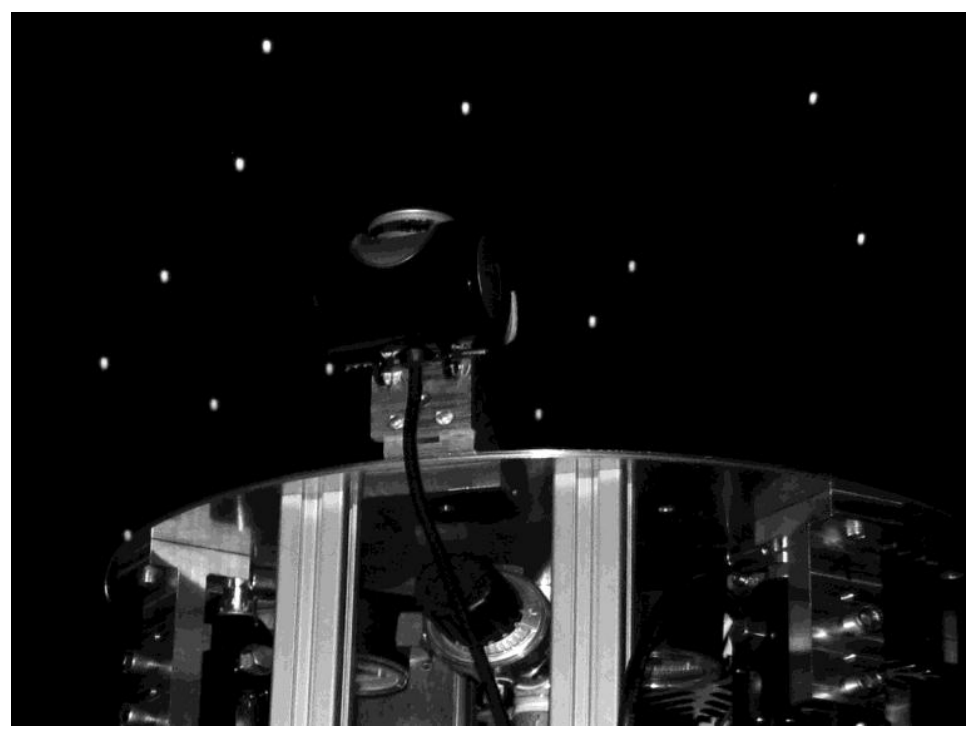

Рис.13. Веб-камера на крышке макета

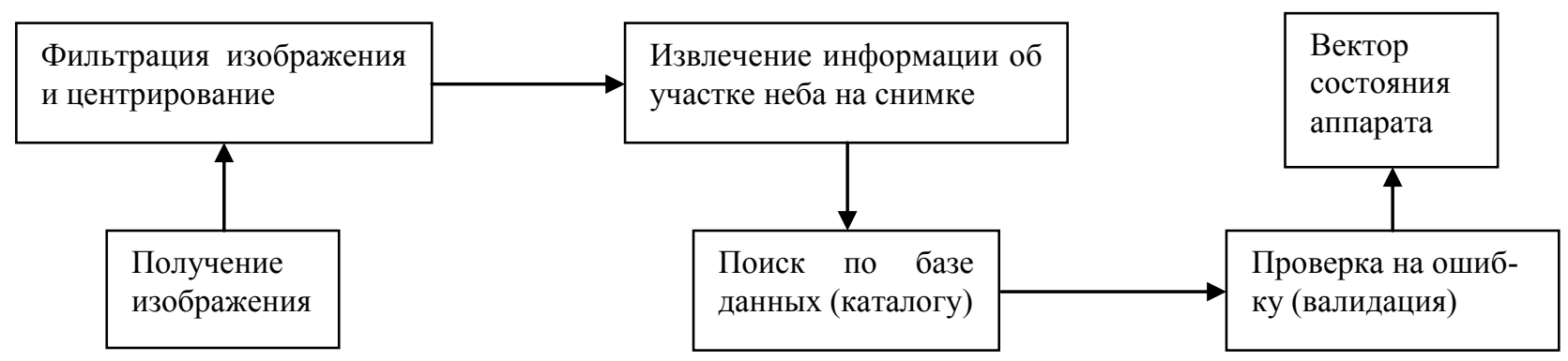

Рис. 14. Циклограмма процесса идентификации участка звездного неба

После получения изображения производится сегментация изображения: картинка преобразуется в двоичный формат, фильтруется, чтобы оставить только яркие точки, после чего вычисляется центроид каждой звезды (рис. 15).

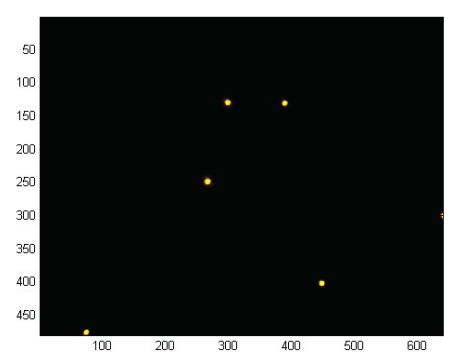

Оригинальная

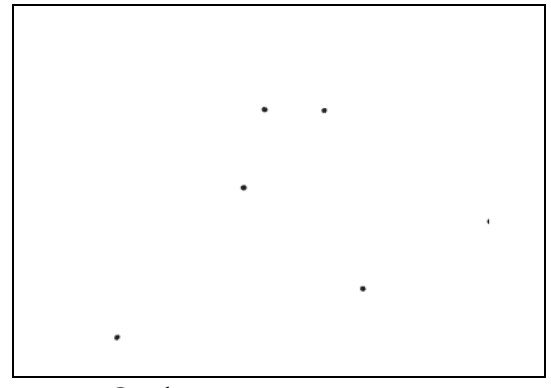

Отфильтрованная

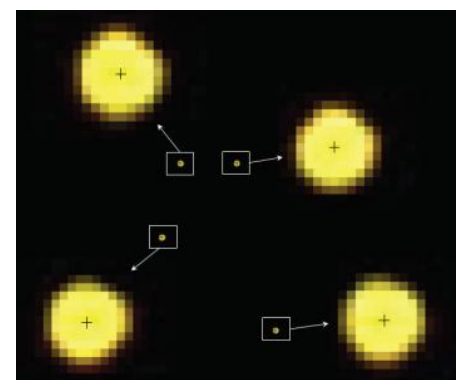

Центроиды

Рис. 15. Сегментирование изображения

В процессе распознавания используется "planar angle method", то есть строятся треугольники согласно разбиению Делоне, рассчитываются углы в них, которые потом используются в поиске по таблице. Поиск ведется с учетом допуска из-за возможных погрешностей. Оценка позиции звездного датчика строится на основе собранной информации. 
В работе [12] в качестве недостатков такой системы определения движения называются достаточно большие по времени вычислительные затраты на обработку снимка и поиск по базе данных (около 0.6 секунд на один снимок). Кроме того, система определения плохо работает при больших (больше $0.3 \mathrm{~m} / \mathrm{c}$ ) скоростях макета, так как изображение в этом случае размазывается и не удается достаточно точно определить центр светимости звезд.

\section{Навигация по изображению объекта}

В работе [14] описан метод определения относительного положения и ориентации подвижного макета на аэродинамическом столе, основанный на обработке фотоснимка опорного объекта с известными геометрическими параметрами. Основная идея метода заключается в следующем: по анализу снимка второго макета (рис. 12), а именно по размерам его освещенной части, вычисляются расстояние до этого тела и угол между направлением на тело и направлением на источник света. В целях упрощения расчётов и увеличения точности в качестве центрального тела берется цилиндр. В эксперименте, изложенном в работе, на полом железном цилиндре была закреплена полоса белой ткани, остальная его часть была задрапирована (рис. 16). Исходя из расстояния до источника света и его сравнительно небольших размеров, можно считать в первом приближении, что центральное тело освещается параллельным пучком света. По мере движения макета производимые с некоторой периодичностью $(\Delta \mathrm{t} \approx 2$ сек) снимки обрабатывались на бортовом компьютере макета. На их основе работал алгоритм поддержания заданного типа движения.
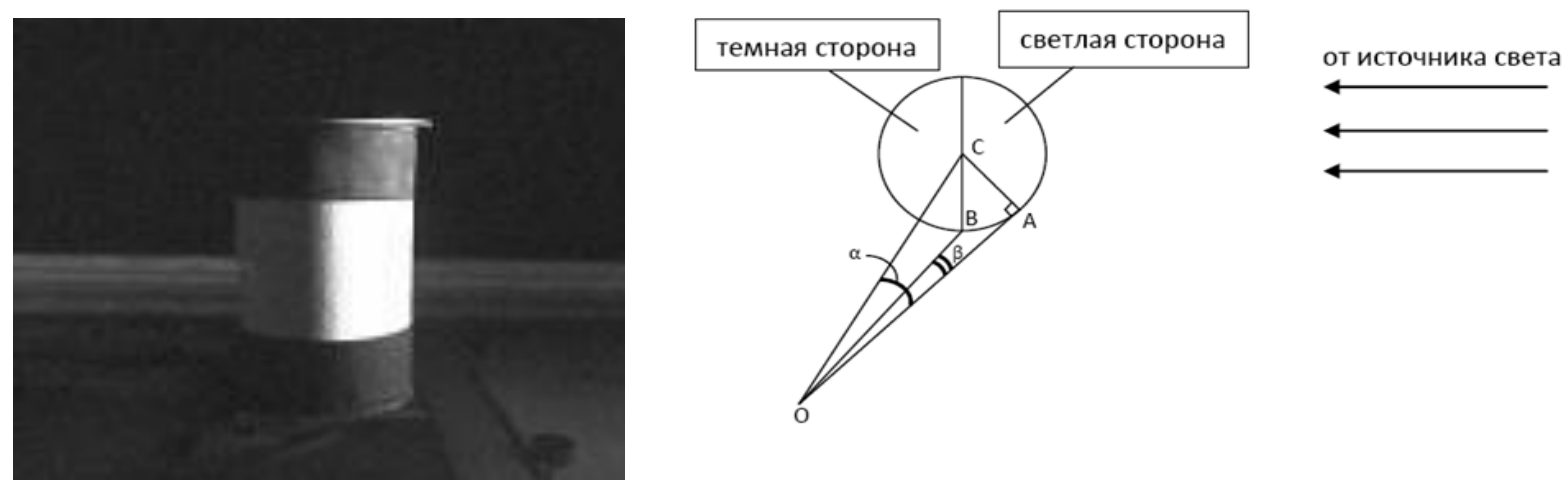

Рис. 16. Центральное тело и схема освещения (вид сверху)

Существуют принципиальные недостатки этого метода определения движения. Во-первых, имеется область засветки - область пространства, в которой в объектив камеры попадает источник света, что делает невозможным корректную обработку снимка. Размер этой области варьируется в зависимости от поля зрения камеры и углового размера источника и в проведённых экспериментах соответствует угловому размеру порядка 30 градусов. Вторым, менее существенным недостатком является неоднозначность определения положения макета, когда макет, центральное тело и источник света располагаются практически вдоль одной прямой. 
Другой подход для навигации по изображению второго макета (или фиксированного объекта) заключается в использовании алгоритмов, которые на видеоряде способны выделять реперные точки. Например, в работе [15] используется алгоритм IBVS (Image Based Visual Sensing), оценивающий относительное движение макета PINOCCHIO по видеоряду цели заранее неизвестной формы (рис. 17). Алгоритм на текущем изображении находит особенности (точки, линии), выделяющиеся по контрасту, цвету и т.П., и соотносит с особенностями на предыдущих кадрах. После того как алгоритм находит совпадения на основе взаимного расположения реперных точек, становится возможным оценить положение камеры относительно системы координат, связанной с наблюдаемым объектом.
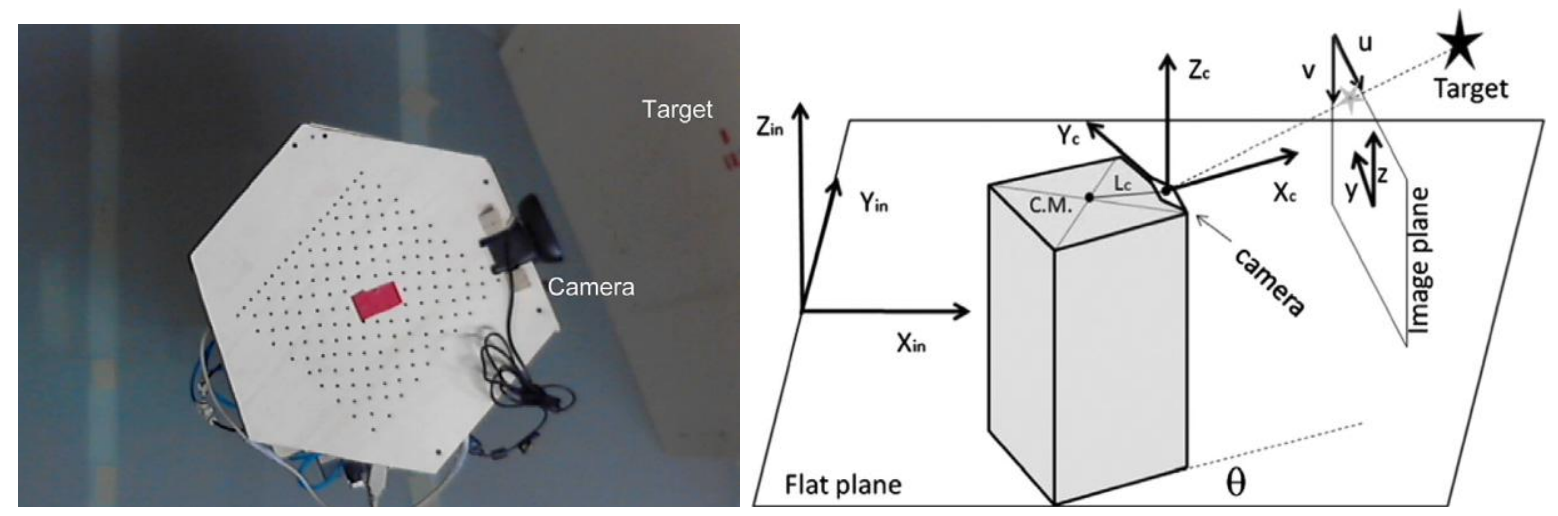

Рис. 17. Макет PINOCCHIO и определение движения по изображению [15]

\section{Навигация по меткам на макете}

Чаще всего для осуществления навигации на столе с помощью обработки видеоизображения на макеты (или составные части макетов) устанавливаются специальные метки особой формы или светящиеся светодиоды. Изображение меток или положение светодиодов на макете заранее известны. Метки, как правило, являются плоскими и максимально контрастными. Например, в [16] в качестве меток использовались черные пятиугольники с уникальными бинарными символами внутри. Метки устанавливаются на все элементы макета, движение которых необходимо определить, а также могут быть установлены на поверхность стола для определения положения камеры относительно стола. Поэтому, как показано на рис. 18, метки находятся как на каждом элементе манипулятоpa, на самом макете, так и на поверхности стола. 


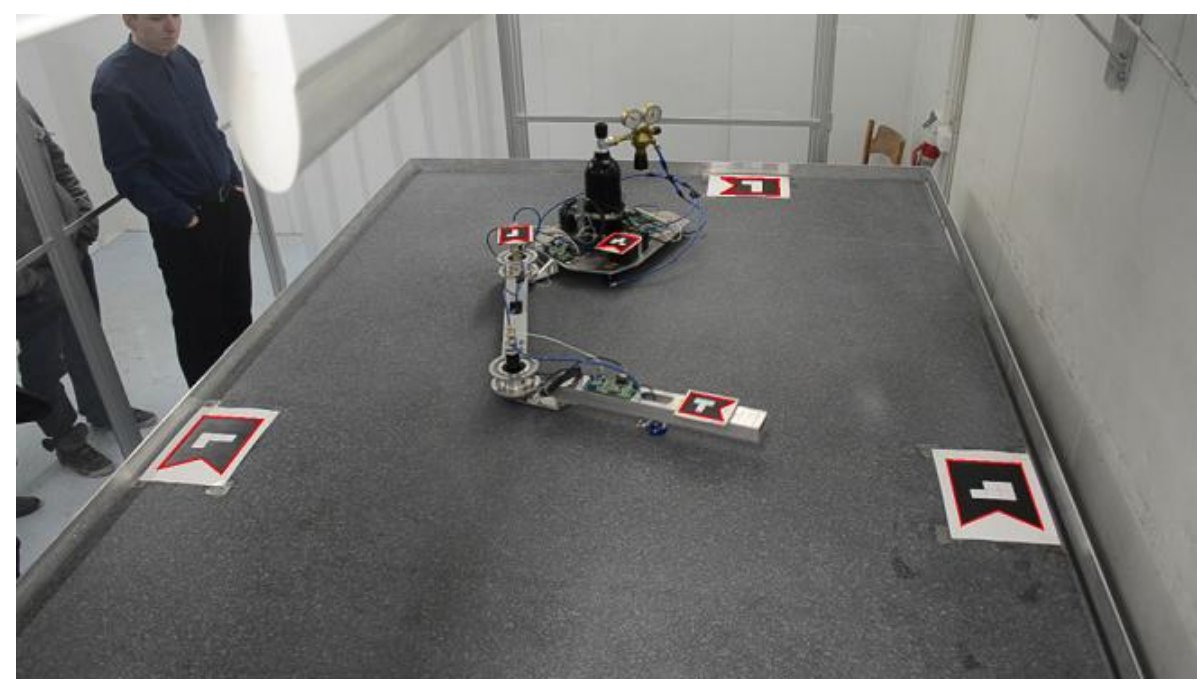

Рис. 18. - Метки на макете с роботизированным манипулятором [16]

Особая форма меток позволяет улучшить их распознавание. В работе [17] выбраны реперные точки с вложенной структурой, причем взаимное расположение точек несимметрично и неоднородно, чтобы избежать неоднозначности распознавания (рис. 19).
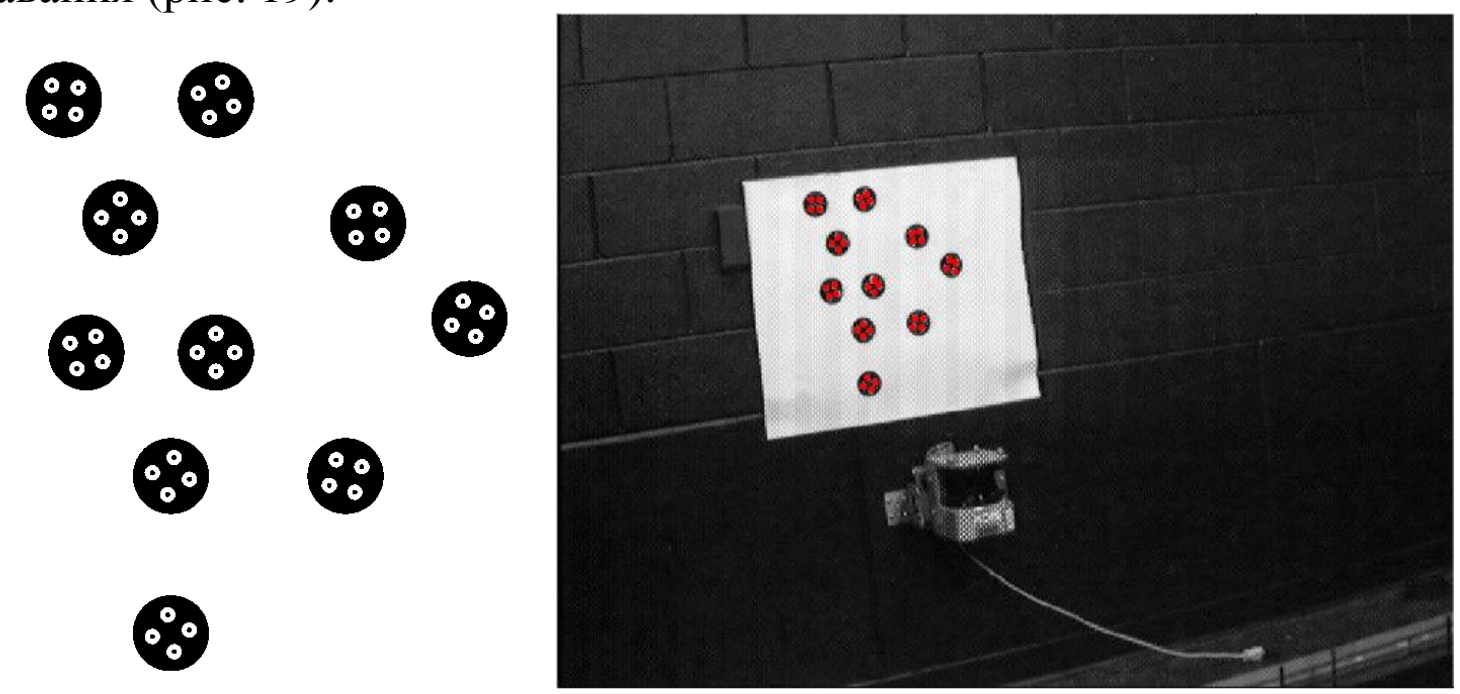

Рис.19. Реперные точки и их распознавание

Улучшить распознавание и отсеять кандидатов на реперные точки можно также с помощью неоднородности распознаваемого изображения. Так, на макеTax SPHERES для относительной навигации использовались достаточно простые круги, два из которых были выделены жирным контуром [18] (рис. 20). 


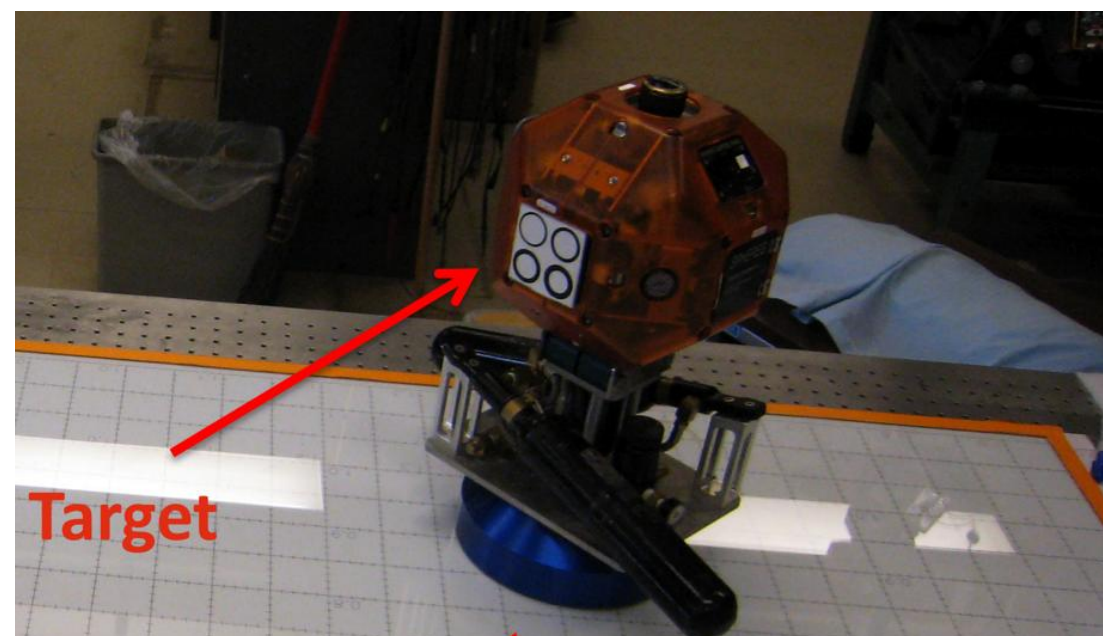

Рис. 20. Макет SPHERES и визуальная метка [18]

Другой пример использования достаточно простой метки - белые точки на черном фоне - на макете SOSS [19]. Однако эта метка не является плоской, как видно из рис. 21. Четыре точки находятся в одной плоскости, а пятая, которая располагается посередине, возвышается на некоторое расстояние. При перемещении макета изображение пятой точки будет менять свое положение между четырьмя остальными, и это, похоже, позволяет получить дополнительную информацию о движении.

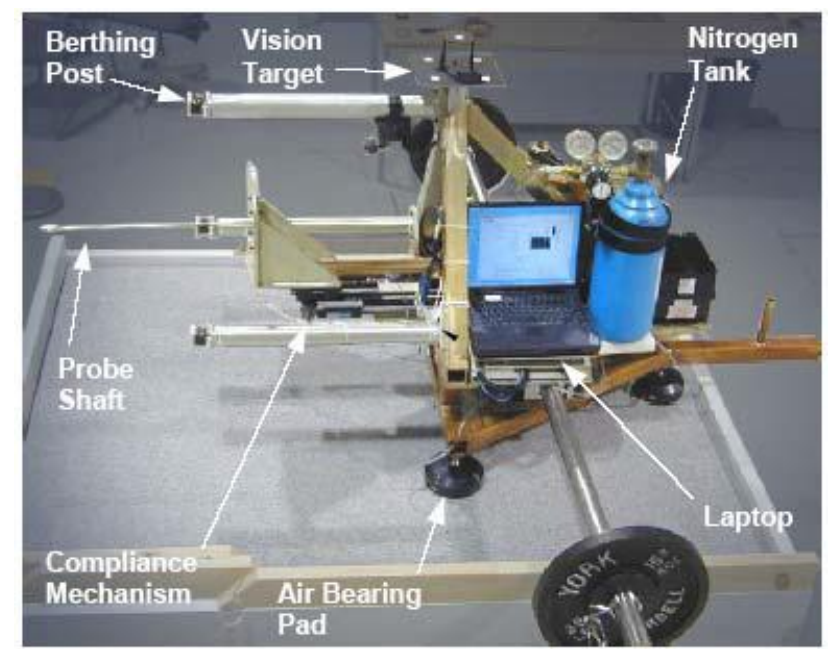

Рис.21. Макет SOSS и визуальная метка [19]

На макетах устанавливаются не только плоские контрастные метки, но и наборы специальных светящихся светодиодов. Использование светодиодов является более надежным способом для идентификации объекта по изображению, так как распознавание реперных точек меньше зависит от условий освещенности, затенения и т.п. Это более приближено к применению в реальных миссиях группового полета спутников для определения относительного движения, как например, в миссии PRIZMA на этапе сближения [20]. Так, на макете лаборатории ADAMUS, имеющем 6 степеней свободы, были установлены 72 светодиода [21]. С помощью обработки изображений с ряда камер, установленных так, 
чтобы их поля зрения пересекались и охватывали всю поверхность стола, удается определить как положение центра масс макета, так и пространственную ориентацию. Система, обеспечивающая навигацию макета, является коммерческой и называется PhaseSpace Impulse System ${ }^{\circledR}$. В состав системы входят наборы из камер с бинокулярным зрением, которые соединяются через сеть Ethernet. Расположение камер вокруг стола изображено на рис. 22.
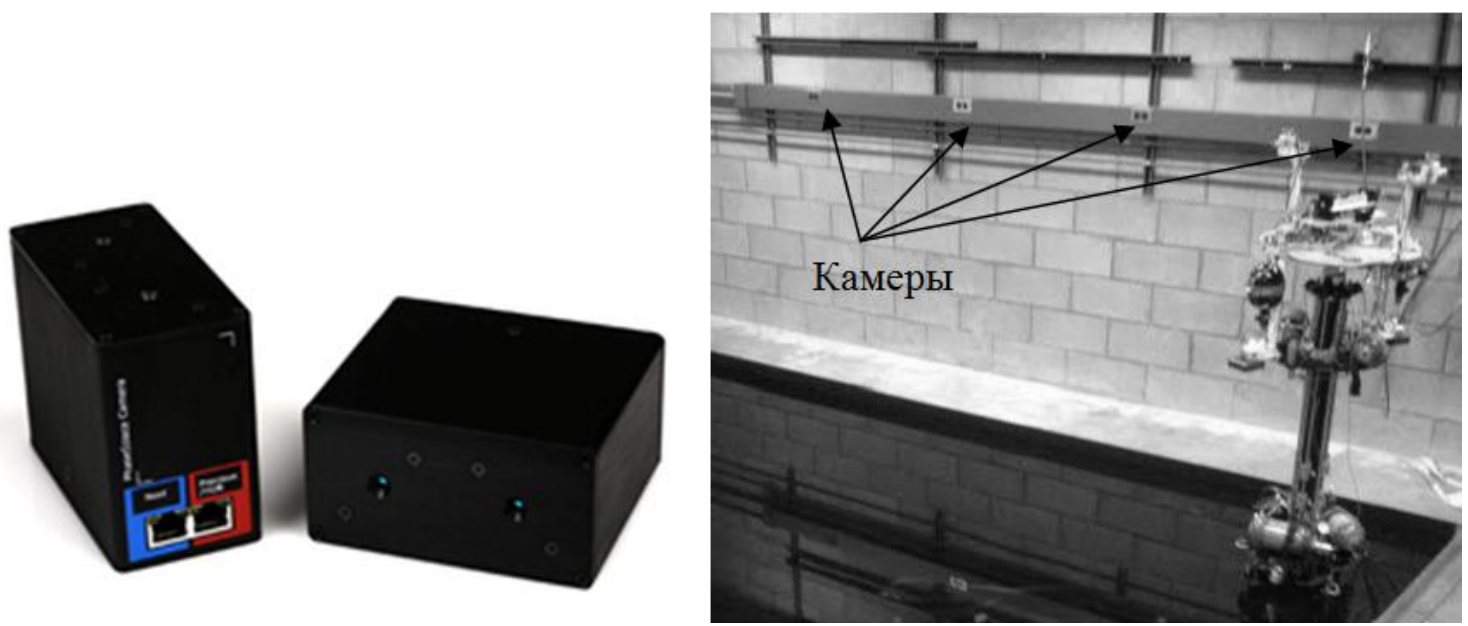

Рис. 22. Камеры для определения движения макета на стенде ADAMUS и их расположение [21]

Другим примером использования коммерческого решения для определения движения на столе является система VICON®, использующая набор монокулярных камер. Эта система использовалась в качестве системы независимых измерений для определения положения макета ASTROS [17]. На верхнюю крышку макета, имеющего 5 степеней свободы, устанавливаются 6 специальных отражающих меток, а камеры располагаются над поверхностью стола как показано на рис. 23.
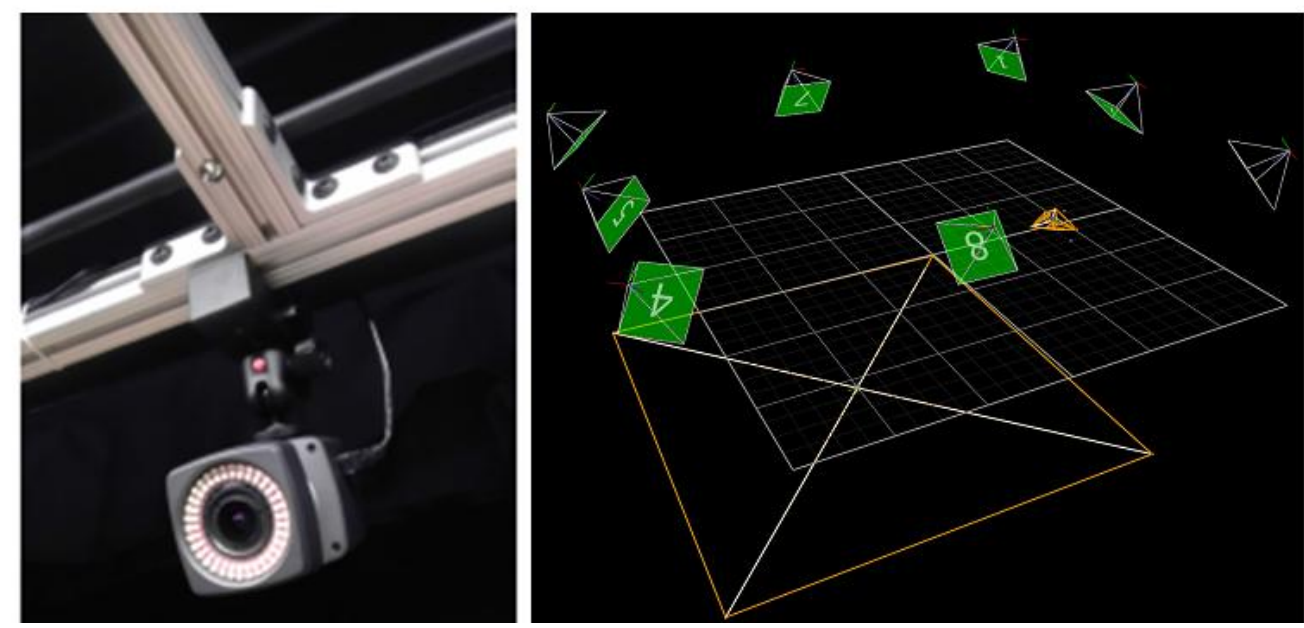

Рис. 23. Камеры для определения движения макета на стенде ASTROS и их расположение [17] 


\section{Лазерные дальномеры}

Лазерные дальномеры активно используются в задачах навигации роботизированных систем и органично вписываются в систему определения движения макетов систем управления спутников на аэродинамическом столе. Как правило, для навигации используются не точечные дальномеры, а лазерные сканеры, измеряющие дальность до сетки точек с некоторым угловым шагом.

В работе [17] в качестве дополнительного средства определения положения макета используется лазерный дальномер SICK LMS200, который с шагом 0.25 град и с миллиметровой точностью на частоте 2 Гц промеряет в плоскости расстояние до всех объектов, находящихся в комнате со столом. Все точки, находящиеся вне периметра стола, отбрасываются, и остается полукруг точек до основания макета, положение которых находится над поверхностью стола (рис. 24). Для определения центра основания полукруг с помощью метода наименьших квадратов достраивается до окружности, и вычисляется положение её центра. Следует отметить, что такой способ использования лазерного дальномера позволяет определить лишь 2 степени свободы из 5 на макете ASTROS.
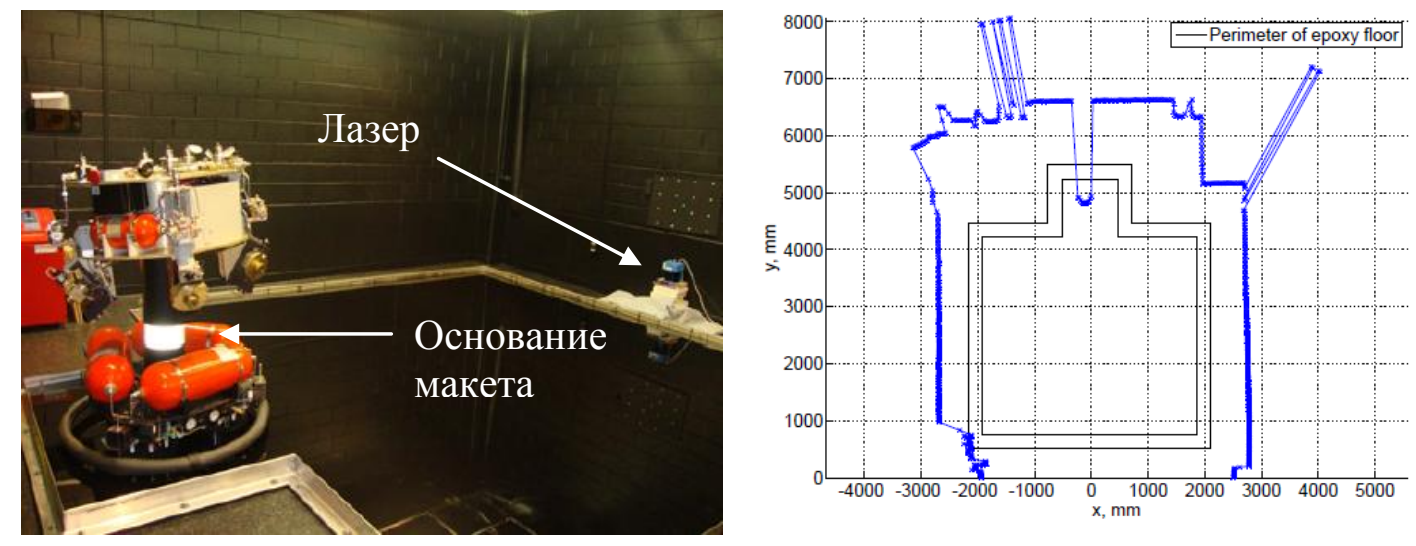

Рис. 24. Лазерный дальномер на стенде ASTROS и его измерения [17]

Лазерные сканеры также использовались в работах [22,23] для определения колебательных движений гибкой конструкции, зафиксированной между двумя макетами (рис. 25). Использование этих сенсоров для нахождения собственных мод в этих работах представляется наиболее естественным, так как по измерениям лазерных дальномеров непосредственно можно определить формы колебаний и отклонение от положения равновесия. 

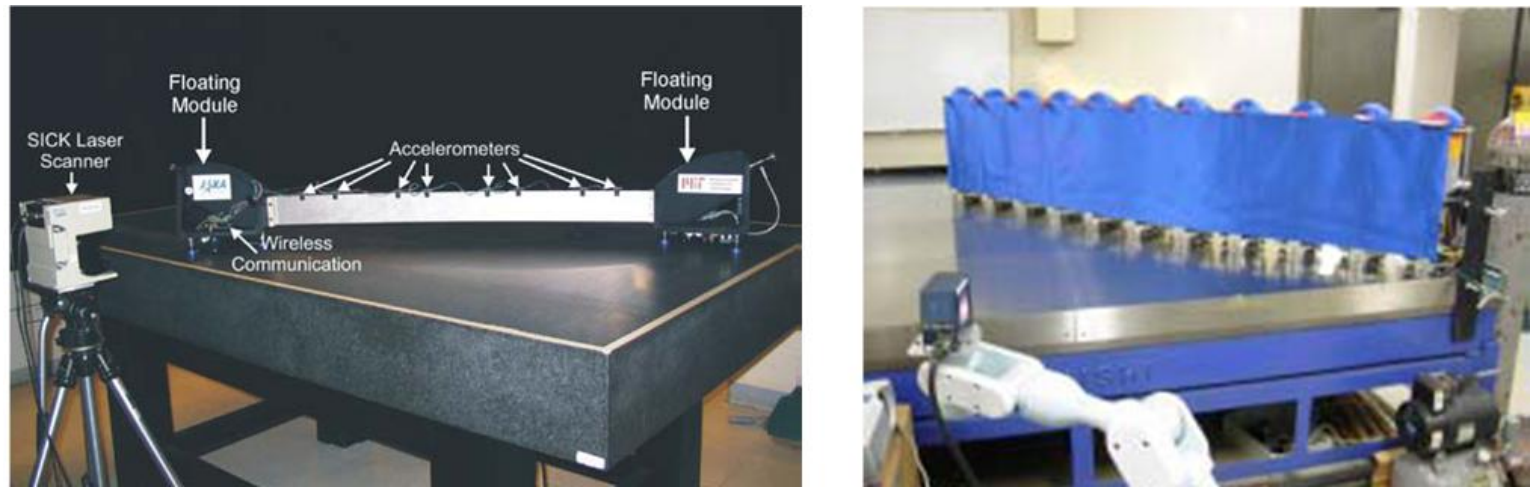

Рис. 25. Лазерные дальномеры для определения колебательных движений гибких конструкции [23]

\section{Инфрракрасные дальномеры}

Инфракрасные дальномеры позволяют с достаточно высокой частотой определить расстояние до объекта и даже составить его 3D модель, что может быть полезно в задачах относительной навигации для стыковки макетов на столе. На макете ASTROS среди прочих сенсоров используется камера типа LiDAR (SwissRanger SR-3000) [17]. Инфракрасные светодиоды испускают модулированную волну с частотой 20 Гц, отраженная от объекта волна попадает на матрицу дальномеров, и в каждом пикселе вычисляется дальность до точек объекта. Зная 3D модель второго макета, можно вычислить его положение и ориентацию относительно макета с дальномерами.

Другой вариант - использовать инфракрасные дальномеры как систему независимых измерений. Коммерческая система DTrack ${ }^{\circledR}$ требует установки как минимум двух специальных инфракрасных камер и набора из специальных отражающих в инфракрасном диапазоне маркеров. Так, на макете стенда FFT на верхней крышке закреплены такие маркеры в виде небольших антенн (рис. 26) [24]. На камерах установлены инфракрасные излучатели, которые испускают волны с частотой 60 Гц. Инфракрасные волны отражаются от маркеров и фиксируются камерами. По пересечению линий направления на маркер с двух камер при известном взаимном положении и ориентации камеры вычисляется положение точки в системе координат, связанной со столом.
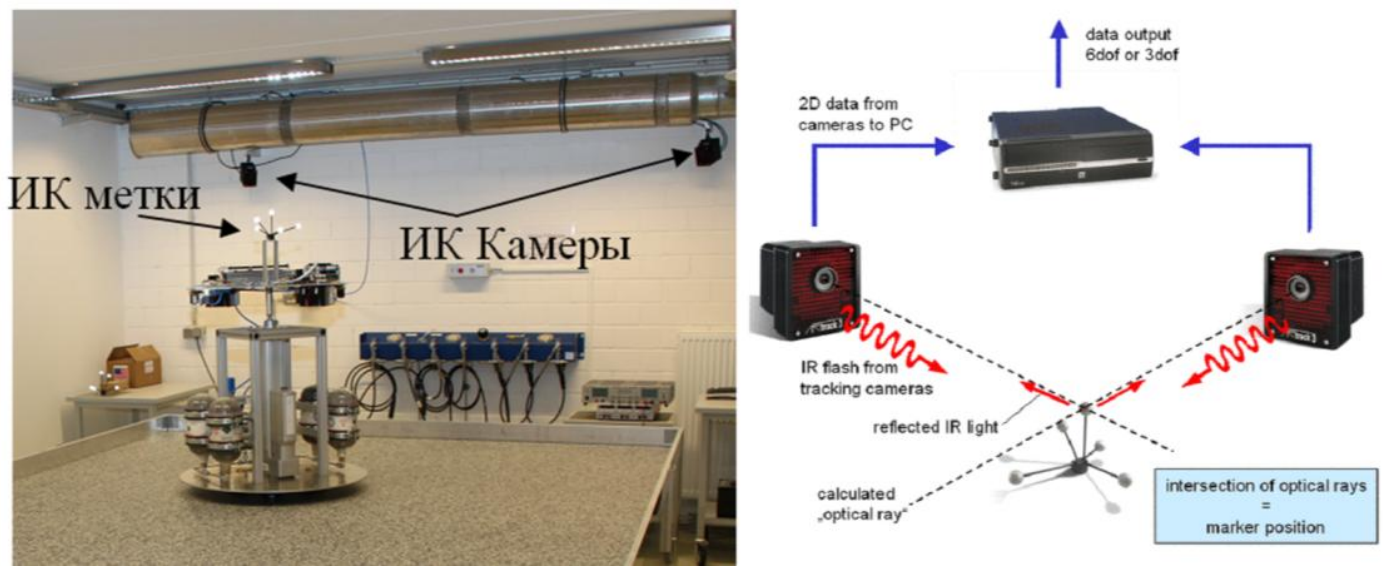

Рис. 26. Инфракрасные дальномеры и специальные метки на макете 


\section{Псевдо GPS}

В работах $[25,26]$ для определения положения центра масс используется система iGPS, имитирующая систему глобального позиционирования, способную работать в помещении. Система состоит из излучателей и приемников. Излучатели производят 2 типа сигналов - лазерный и инфракрасный. Лазеры установлены на вращающемся основании и излучают в двух сходящихся плоскостях. С некоторым периодом излучатель выдает инфракрасный импульс. Измеряя время между приходом сигналов разного типа, можно вычислить направление на приемник. Для вычисления положения приемника на плоскости необходимо иметь минимум 2 излучателя и знать их расположение. Недостаток использования системы iGPS заключается в том, что если на макете установлен только один приемник (как на рис. 27), то определить угловое положение не представляется возможным.
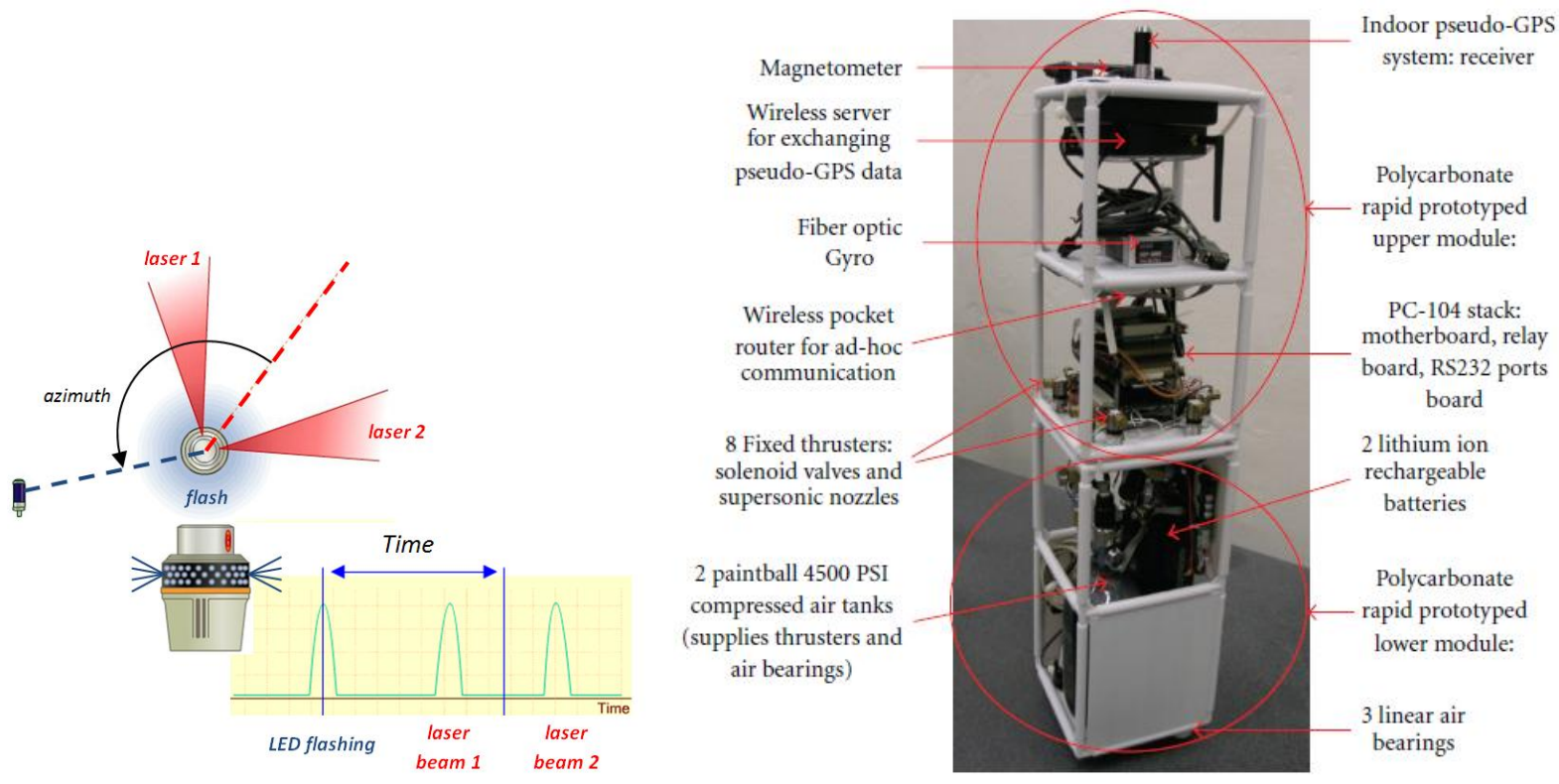

Рис. 27. Излучатель и приемник системы iGPS

\section{Инерциальные датчики}

Позиционные средства навигации - камеры, дальномеры - позволяют напрямую определить положение и ориентацию макетов. Другим вариантом для вычисления пространственного положения является интегрирование измерений инерциальных датчиков - датчика угловой скорости и акселерометра, установленных на самом макете. Однако для этого необходимо знать начальные условия - положение, ориентацию, линейную и угловую скорость макета в начальный момент времени. Другой проблемой использования блока инерциальных датчиков (IMU - Inertial Measurement Unit) является неточное знание ноля измерений, которое может в силу ряда причин меняться со временем. Поэтому, как правило, измерения датчика угловой скорости и акселерометра обрабатываются совместно с позиционными измерениями. 
В работе [12] блок IMU состоит из двух датчиков и микроконтроллера. В качестве датчика угловой скорости используется датчик ADIS 16100 производства фирмы Analog Devices. Точность составляет порядка $\sigma= \pm 0.1 \%$ при частоте выдачи измерений порядка $f=1000 Г ц$. Двухосный инклинометр SCA103T-D04 имеет диапазон измерений $\pm 0.26 g= \pm 2.55 \mathrm{~m} / \mathrm{c}^{2}$. Точность определения ускорения составляет $\sigma= \pm 0.002 \mathrm{M} / \mathrm{c}^{2}$. На рис. 28 изображен блок IMU и сравнение результата интегрирования измерений инклинометра с измерениями положения с помощью звездного датчика. Спустя довольно короткое время оценка положения начинает довольно сильно расходиться.
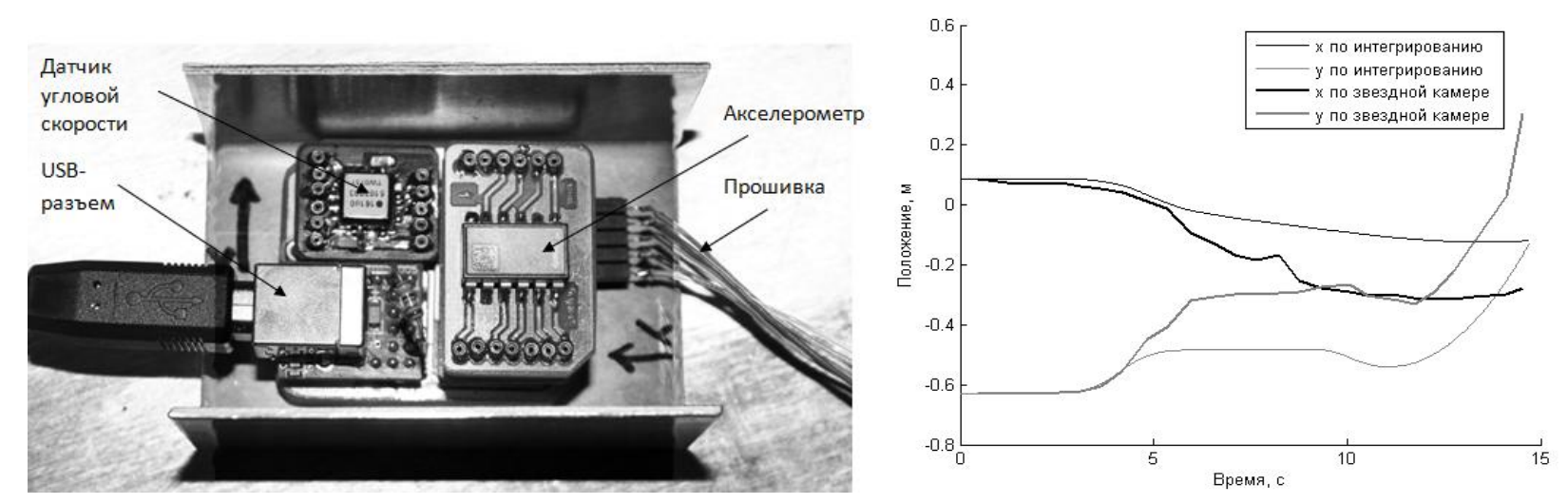

Рис. 28. Блок IMU на стенде LuVeX и результаты интегрирования [12]

Блоки IMU используются почти на всех макетах. Так, на макетах стенда FFT блок IMU состоит из 3 оптоволоконных датчиков угловой скорости и 3 MEMS акселерометров, которые установлены на верхней платформе макета [24]. На стенде ASTROS также измеряются ускорения и угловая скорость.

Акселерометры могут использоваться не только для измерения линейного ускорения макета на поверхности стола, но и для определения колебаний гибких элементов конструкции. Например, в работах [22,23] акселерометры устанавливаются на гибкую планку между макетами (см. рис. 25).

\section{3 Использование аэродинамического стола}

Аэродинамический стол позволяет решить большой спектр задач. Каждая из них имеет особенность в том числе и с точки зрения используемой элементной базы системы управления движением. Поэтому ниже приведены наиболее распространенные задачи, решаемые на столе [27].

\section{Тестирование манипуляторов для космических систем}

Тестирование полномасштабных моделей космических систем было одним из первых приложений аэродинамических столов. Наземное тестирование многозвенных манипуляторов, разрабатываемых для работы в невесомости, практически невозможно в условиях земного притяжения без обезвешивающих механизмов. Аэродинамический стол дает возможность довольно точно имитиро- 
вать плоское движение манипулятора. Основной трудностью, с которой сталкиваются разработчики, является то, что, как правило, тестируют макеты в натуральную величину, что требует создания больших поверхностей.

Примечательной является задача имитации динамики многозвенного манипулятора для Шаттла в натуральную величину - Shuttle Remote Manipulator System [28], который достигал в длину $15.2 \mathrm{M}$, а его масса составляла 410кг. Для этого была создана установка, которую поместили в чистую комнату (рис. 29).

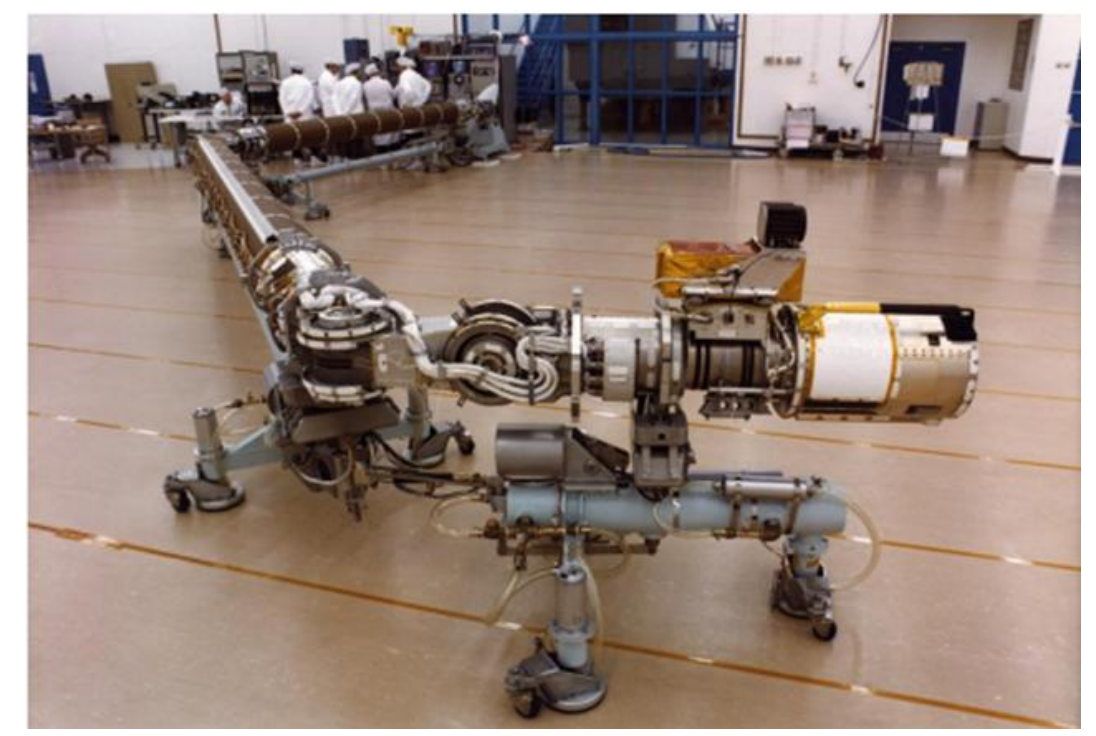

Рис. 29. Установка для моделирования манипулятора Шаттла

Китайский манипулятор тестировался схожим образом [29]. Здесь тестирование проводилось в две стадии, когда трехмерное движение разбивалось на два двухмерных движения, которые тестировались независимо.

До этого речь шла о стендах для полноразмерных экспериментов. Такое далеко не всегда возможно, и в этом случае создается масштабная модель манипулятора, с помощью которой проводится тестирование алгоритмов и численное моделирование динамики. Можно отметить работу [30], где проводится верификация математической модели, заданной системой обыкновенных дифференциальных уравнений, гибкого манипулятора. В Университете Падуи [31] разработан макет для изучения влияния моментов сил реакции, возникающий при движении манипулятора (рис. 30). Как видно из рис. 29 и рис. 30 манипуляторы имеют несколько опор, обеспечивающих обезвешивание всего манипулятора. При этом один конец манипулятора зафиксирован относительно стола. Такая фиксация фактически исключает тестирование алгоритмов управления КА, к которому подобный манипулятор крепится. 


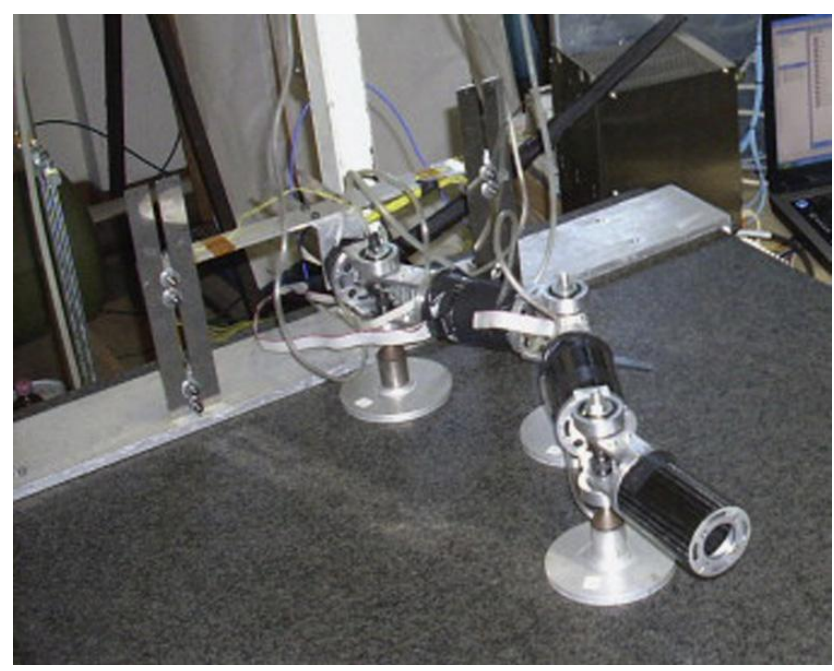

Рис. 30. Макет манипулятора в Университете Падуи

Использование манипулятора с двумя свободными концами приближает динамику макета на столе к динамике КА в условиях орбитального полета и привносит качественно новые особенности. По этой причине, по-видимому, наибольшая группа работ посвящена разработке и использованию подобных систем. Еще в 80-х годах в Стэндфордском университете были проведены эксперименты по тестированию стратегий управления для манипулятора со свободными концами [32]. В работах [33,34] рассматривается макет спутника с манипуляторами для технического обслуживания других КА на орбите (рис. 31). Рассматриваются вопросы отработки и оптимизации управления с помощью маховиков и реактивных двигателей.

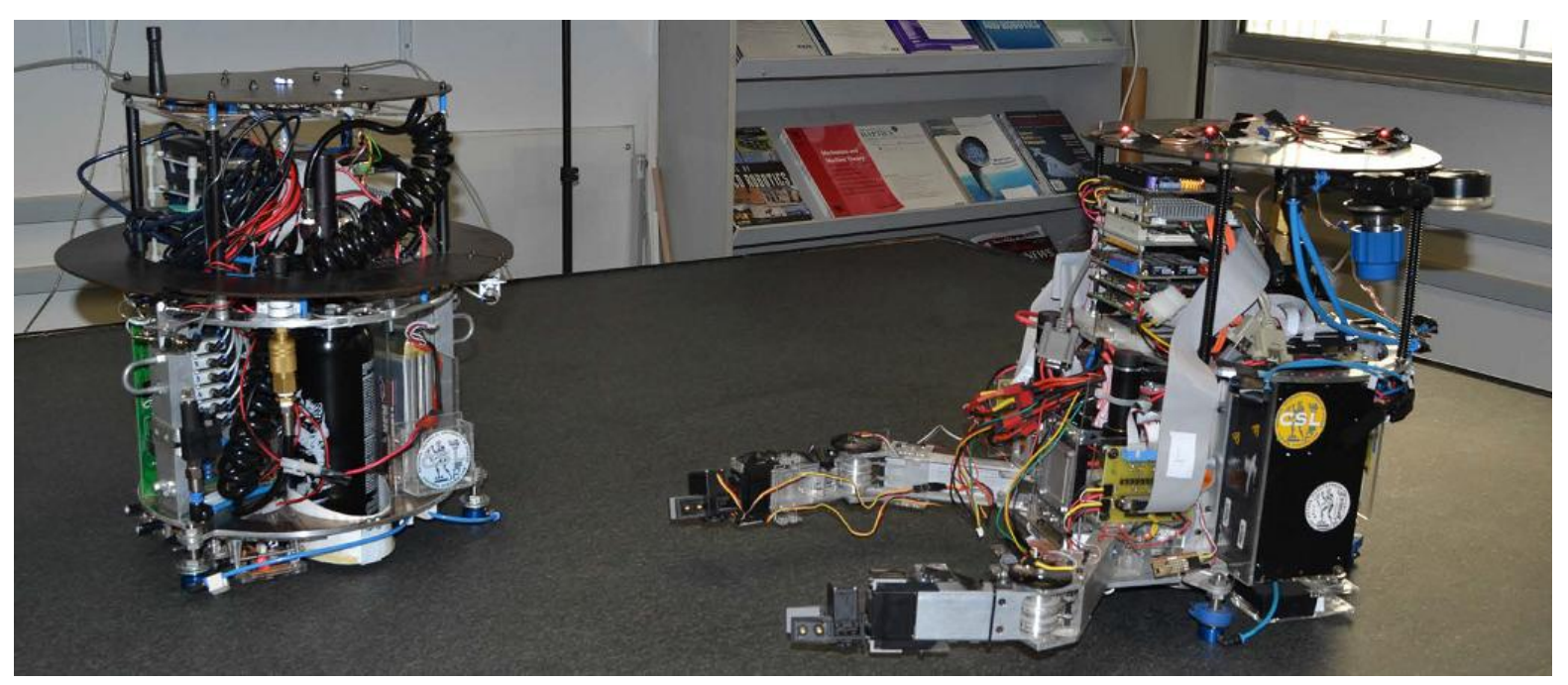

Рис. 31. Макеты системы управления движением и захвата в Национальном техническом университете Афин

Вопросы отработки взаимодействия группировки роботов с большой гибкой космической конструкцией также рассматривается в качестве объекта лабораторной отработки на аэродинамическом столе [9]. 


\section{Групповые полеты}

Говоря о группировке спутников, нельзя не упомянуть о задачах управления спутниками в групповом полете. Групповым полетом называется совместное движение спутников на небольшом (по сравнению с радиусом орбиты) расстоянии. Использование аэродинамического стола дает широкие возможности по отработке управления относительным движением.

Основными задачами здесь являются задачи создания, поддержания и изменения формации [35], [36]. При этом, как правило, рассматриваются задачи лабораторной верификации методов и средств управления и определения движения. Например, в работе [37] было проведено тестирование алгоритма определения 12-мерного вектора состояния двух близколетящих спутников с помощью видеокамеры, а в [38] затрагиваются вопросы верификации робастного управления $\left(H_{\infty}\right)$ для решения задачи сближения и стыковки. При этом в лабораторных условиях тестируется не только точность и быстродействие алгоритмов, но и возможность их применимости в условиях ограниченных вычислительных возможностей (иными словами - на бортовом компьютере). Например, в работе [39] показана возможность применения управления на основе уравнения Риккати в системе реального времени на бортовом компьютере. А в [40] верифицируется техника управления с помощью широтно-импульсного модулятора реактивным двигателем спутника, преследующего полуактивный КА. Работа [26] посвящена тестированию линейно-квадратичного регулятора для группы макетов, а [41] - ляпуновского управления для реактивных двигателей нерегулируемой тяги. Таким образом, аэродинамические столы допускают тестирование и верификацию практически всех групп алгоритмов управления, что позволяет использовать различное сочетание алгоритмов и средств управления макетами на аэродинамическом столе.

\section{Другие эксперименты}

Первые две задачи являются наиболее широко представленными в литературе и проработанными на практике. Тем не менее, существует еще ряд задач, которые решаются на аэродинамическом столе и могут быть потенциально интересны.

Первый класс задач относится к тросовым спутниковым системам. К настоящему моменту подобные миссии имеют высокую степень неудачи [42], таким образом, лабораторные эксперименты крайне необходимы. В работе [43] продемонстрирована на примере трех макетов, соединенных тросами, возможность отработки в лаборатории подобных систем. Управление положением и ориентацией осуществлялось с помощью реактивных двигателей. Для этой демонстрации использовался стол размером $3 \times 5 \mathrm{~m}^{2}$. В [44] исследуется динамика троса в лабораторных условиях. К сожалению, сама миссия оказалась неудачной, и трос удалось выпустить только на 22 метра. Причиной неудачи оказался неучет температурной деформации на освещенной стороне орбиты. 
Следующий класс задач относится к стыковке. Наибольший интерес здесь представляет стыковка с некооперирующей целью [45], которой может являться, например, объект космического мусора. В ходе таких экспериментов тестируются не только алгоритмы управления движением, но и модели контактного взаимодействия и аппаратная часть, обеспечивающая захват целевого объекта. При этом конечная цель стыковки в таких случаях может быть или увод с орбиты, или же, напротив, ремонт и увеличение срока активного существования КА.

Интересной является задача имитации посадки в лабораторных условиях. Общая схема такой экспериментальной установки приведена на рис. 32 [27]. В подобных экспериментах тестируется оборудование для посадки на космические тела с малым уровнем гравитации. Например, в [46] тестируется шасси для посадки на мягкий грунт.

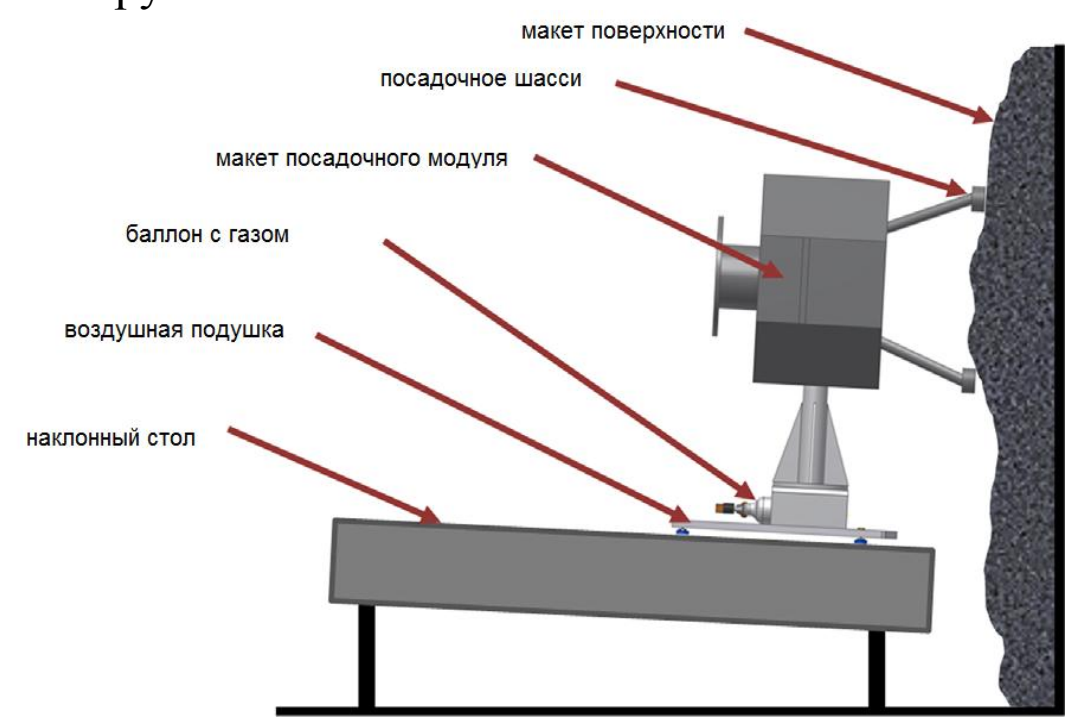

Рис. 32. Схема отработки посадки

В целом, как можно видеть, аэродинамические столы предоставляют широкий спектр возможностей по лабораторному тестированию космических миссии. В Таблице приведен перечень наиболее активно использующихся аэродинамических столов с основными характеристиками.

Таблица - Характеристики аэродинамических столов [27]

\begin{tabular}{|c|c|c|c|c|c|}
\hline Организация & Страна & $\begin{array}{c}\text { Размер, } \\
\mathrm{M}^{2}\end{array}$ & $\begin{array}{c}\text { Материал } \\
\text { поверхности }\end{array}$ & $\begin{array}{c}\text { Степени } \\
\text { свободы }\end{array}$ & Основная задача \\
\hline $\begin{array}{c}\text { Университет } \\
\text { Павии }\end{array}$ & Италия & $2 \times 2$ & стекло & $\begin{array}{c}\text { фиксирован- } \\
\text { ное } \\
\text { основание }\end{array}$ & $\begin{array}{c}\text { управление } \\
\text { нежесткими } \\
\text { манипуляторами }\end{array}$ \\
\hline $\begin{array}{c}\text { Харбинский } \\
\text { технологический } \\
\text { университет }\end{array}$ & Китай & $4.2 \times 3.6$ & $\begin{array}{c}\text { гранит, со- } \\
\text { ставной } \\
\text { фиксирован- } \\
\text { ное } \\
\text { основание }\end{array}$ & $\begin{array}{c}\text { тестирование } \\
\text { манипуляторов }\end{array}$ \\
\hline $\begin{array}{c}\text { Университет } \\
\text { Тохоку }\end{array}$ & Япония & $1 \times 1$ & мрамор & 3 & $\begin{array}{c}\text { манипулятор со } \\
\text { свободными } \\
\text { концами, } \\
\text { стыковка }\end{array}$ \\
\hline
\end{tabular}




\begin{tabular}{|c|c|c|c|c|c|}
\hline Организация & Страна & $\begin{array}{c}\text { Paзмер, } \\
\text { м }^{2}\end{array}$ & $\begin{array}{c}\text { Материал } \\
\text { поверхности }\end{array}$ & $\begin{array}{l}\text { Степени } \\
\text { свободы }\end{array}$ & Основная задача \\
\hline $\begin{array}{c}\text { Массачусетский } \\
\text { технологический } \\
\text { институт }\end{array}$ & США & $1.3 \times 2.2$ & гранит & 3 & $\begin{array}{c}\text { манипулятор со } \\
\text { свободными } \\
\text { концами, } \\
\text { нежесткие } \\
\text { конструкции } \\
\end{array}$ \\
\hline $\begin{array}{c}\text { Токийский } \\
\text { технологический } \\
\text { институт }\end{array}$ & Япония & $1.8 \times 1.8$ & стекло & 3 & $\begin{array}{c}\text { манипулятор со } \\
\text { свободными кон- } \\
\text { цами }\end{array}$ \\
\hline $\begin{array}{c}\text { Комическое } \\
\text { подразделение } \\
\text { MDA }\end{array}$ & Канада & $1.93 \times 1.52$ & гранит & 3 & стыковка \\
\hline $\begin{array}{c}\text { Национальный } \\
\text { технический } \\
\text { университет Афин }\end{array}$ & Греция & $2.2 \times 1.8$ & гранит & 3 & $\begin{array}{c}\text { манипулятор со } \\
\text { свободными } \\
\text { концами }\end{array}$ \\
\hline $\begin{array}{c}\text { Космический } \\
\text { исследовательский } \\
\text { центр }\end{array}$ & Польша & $2 \times 3$ & гранит & 3 & $\begin{array}{c}\text { манипулятор со } \\
\text { свободными } \\
\text { концами, посадка }\end{array}$ \\
\hline $\begin{array}{c}\text { Стэндфордский } \\
\text { университет }\end{array}$ & США & $2.74 \times 3.66$ & гранит & 3 & групповые полеты \\
\hline $\begin{array}{c}\text { Массачусетский } \\
\text { технологический } \\
\text { институт }\end{array}$ & США & $\begin{array}{c}8- \\
\text { угольник } \\
\mathrm{d}=5.1\end{array}$ & $\begin{array}{c}\text { пол из эпок- } \\
\text { сидной смолы }\end{array}$ & 3 & $\begin{array}{c}\text { манипулятор со } \\
\text { свободными } \\
\text { концами, нежест- } \\
\text { кие конструкции, } \\
\text { групповые полеты }\end{array}$ \\
\hline $\begin{array}{c}\text { Школа повышения } \\
\text { квалификации } \\
\text { офицерских } \\
\text { кадров ВМС США }\end{array}$ & США & $4.9 \times 4.3$ & $\begin{array}{c}\text { пол из эпок- } \\
\text { сидной смолы }\end{array}$ & 3 & групповые полеты \\
\hline $\begin{array}{c}\text { Лаборатория } \\
\text { реактивного } \\
\text { движения }\end{array}$ & США & $7.3 \times 8.5$ & $\begin{array}{c}\text { металлические } \\
\text { панели }\end{array}$ & 3 & групповые полеты \\
\hline $\begin{array}{c}\text { Технологический } \\
\text { университет } \\
\text { Джорджии }\end{array}$ & США & $3.66 \times 3.66$ & $\begin{array}{c}\text { пол из эпок- } \\
\text { сидной смолы }\end{array}$ & 5 & групповые полеты \\
\hline $\begin{array}{c}\text { Институт } \\
\text { космических } \\
\text { систем }\end{array}$ & Германия & $4 \times 2.5$ & гранит & 5 & групповые полеты \\
\hline $\begin{array}{c}\text { Ливерморская на- } \\
\text { циональная } \\
\text { лаборатория }\end{array}$ & США & $1.5 \times 7.3$ & стекло & 5 & групповые полеты \\
\hline $\begin{array}{c}\text { Политехнический } \\
\text { институт } \\
\text { Ренсселера }\end{array}$ & США & $3.96 \times 4.57$ & $\begin{array}{c}\text { пол из эпок- } \\
\text { сидной смолы }\end{array}$ & 6 & групповые полеты \\
\hline
\end{tabular}

Из таблицы видно, что основные приложения для подобного оборудования - это тестирование манипуляторов и групповые полеты (с ними тесто связана задача стыковки). Наиболее часто встречающееся число степеней свободы - 
три на один макет. Это связано с технической трудностью реализации большего числа степеней. Обычно это комбинация аэродинамического стола и аэродинамического подвеса.

\section{Заключение}

Созданный по заказу ИПМ компанией Спутникс стенд КОСМОС для имитации движения макетов системы управления микроспутников является удобным инструментом для тестирования алгоритмов управления движением. Спектр задач, которые могут быть решены на стенде, охватывает области задач, связанных с групповыми полетами микроспутников, движением с тросом, имитацией движения гибких конструкций и космических манипуляторов. Обзор показал, что удобство разработанного стенда по сравнению с зарубежными аналогами заключается в том, что воздушная подушка создается не самими макетами, а с помощью избыточного давления под поверхностью стола. Однако такой способ создания плоского невозмущенного движения обуславливает аэродинамические возмущения, действующие на макеты, которые должны быть исследованы и учтены в алгоритме управления. 


\section{Литература}

1. СПУТНИКС - Орбикрафт [Электронный pecypc]. URL: http://sputnix.ru/ru/products/eduru/orbikraft-1-0 (дата обращения: 02.12.2016).

2. Коптев М.Д., Прошунин Н.Н., Иванов Д.С. Определение движения макетов системы управления микроспутников на аэродинамическом столе с использованием видеокамеры // Препринты ИПМ им. М.В. Келдыша. 2015. № 109. $32 \mathrm{c}$.

3. Schlotterer M., Theil S. Testbed for on-orbit servicing and forma tion flying dynamics emulation // Proc. AIAA Guid. Navig. Control Conf. Toronto, Canada. 2010. $17 \mathrm{p}$.

4. Sabatini M., Farnocchia M., Palmerini G.B. Design and tests of a frictionless 2D platform for studying space navigation and control subsystems // Proc. IEEE Aerosp. Conf. Big Sky. 2012. 12 p.

5. Papadopoulos E. et al. The NTUA space robot simulator: design and results // Proc. 10th ESA Work. Adv. Sp. Technol. Robot. Autom. ESTEC Noordwijk. 2008. $8 \mathrm{p}$.

6. Rybus $T$. et al. New planar air-bearing microgravity simulator for verification of space robotics numerical simulations and control algorithms // Proc. 12th Symp. Adv. Sp. Technol. Robot. Autom. ESTEC, Noordwijk. 2013. 8 p.

7. Ivanov D. et al. Laboratory Facility for Simulation and Verification of Formation Motion Control Algorithms // Small Satell. Mission. Earth Obs. New Dev. Trends. 2010. P. 267-277.

8. Yoshida K., Umetani Y. Control of space free-flying robot // Proc. 29th Conf. Decis. Control. Hono- lulu, Hawaii. 1990. 6 p.

9. Boning P. et al. An experimental study of the control of space robot teams assembling large flexiblespace structures // Proc. 9th Int. Symp. Artif. Intell. Robot. Autom. Sp. 2008. 8 p.

10. Tsiotras P. ASTROS: A 5 DOF experimental facility for research in space proximity operations // Proc. 37th AAS Guid. Control Conf. Breckenridge. 2014. $14 \mathrm{p}$.

11. Segal S., Carmi A., Gurfil P. Stereovision-Based Estimation of Relative Dynamics Between Noncooperative Satellites: Theory and Experiments // IEEE Trans. Control Syst. Technol. 2014. Vol. 22, № 2. P. 568-584.

12. Иванов Д.С. et al. Система определения положения и ориентации макета спутника на основе блока инерциальных датчиков и звездного датчика // Препринты ИПМ им. М.В.Келдыша. 2011. № 24.30 с.

13. Биндель Д. et al. Лабораторный стенд для верификации алгоритмов управления группировкой спутников // Известия РАН. Теория и системы управления. 2009. Т. 48, № 5. С. 109-117.

14. Иванов Д.С., Овчинников М.Ю., Трофимов С.П. Применение фотограмметрического метода в задаче автономного определения относительного движения группы макетов // Препринты ИПМ им. М.В. 
Келдыша. 2010. № 5. 22 с.

15. Sabatini M. et al. Image based control of the "PINOCCHIO" experimental free flying platform // Acta Astronaut. Elsevier, 2014. Vol. 94, № 1. P. 480-492.

16. Rybus $T$. et al. New planar air-bearing microgravity simulator for verification of space robotics numerical simulations and control algorithms // 12th ESA Symp. Adv. Sp. Technol. Robot. Autom. 2013. Vol. 1, № 1. P. 1-8.

17. Tsiotras P. A 5dof Experimental Platform for Research in Spacecraft Proximity Operations // AAS Guid. Control Conf. 2014. Vol. 14, № 114. P. 14.

18. Tweddle B.E., Saenz-Otero A. Relative Computer Vision-Based Navigation for Small Inspection Spacecraft // J. Guid. Control. Dyn. 2015. Vol. 38, № 5. P. 969978.

19. Ma O., Yang G. Validation of a satellite docking simulator using the SOSS experimental testbed // IEEE Int. Conf. Intell. Robot. Syst. 2006. № November 2016. P. 4115-4120.

20. Noteborn R. Flight Results from the PRISMA Optical Line of Sight Based Autonomous Rendezvous Experiment // Proc. 4th Int. Conf. Spacecr. Form. Fly. Mission. an Technol. May 2011, Montr. Canada. 10 p.

21. Saulnier K. et al. Operational Capabilities of a Six Degrees of Freedom Spacecraft Simulator // AIAA Guid. Navig. Control Conf. 2013. P. 1-15.

22. Lichter M.D. Vibration Estimation of Flexible Space Structures using Range Imaging Sensors // Int. J. Rob. Res. 2006. Vol. 25, № 10. P. 1001-1012.

23. Bilton A. et al. Sensor architecture for the robotic control of large flexible space structures // J. F. Robot. 2007. Vol. 24, № 4. P. 297-310.

24. Schlotterer M., Theil S. Testbed for on-orbit servicing and formation flying dynamics emulation // Proc. AIAA Guid. Navig. Control Conf. 2010. 17 p.

25. Hall J.S., Romano M. Laboratory Experimentation of Guidance and Control of Spacecraft During On-orbit Proximity Maneuvers // Mechatron. Syst. Simulation, Model. Control. 2007. P. 187-222.

26. Bevilacqua R. et al. Guidance Navigation and Control for Autonomous Multiple Spacecraft Assembly: Analysis and Experimentation // Int. J. Aerosp. Eng. 2011. Vol. 2011. P. 1-18.

27. Rybus T., Seweryn K. Planar air-bearing microgravity simulators: Review of applications, existing solutions and design parameters // Acta Astronaut. 2016. Vol. 120. P. 239-259.

28. Jorgensen G., Bains E. SRMS history, evolution and lessons learned // Proc. AIAA Sp. Conf. Expo. Long Beach. 2011. 24 p.

29. Gao X.H. et al. Development of the Chinese intelligent space robotic system // Proc. IEEE/RSJ Int. Conf. Intell. Robot. Syst. 2006. 8 p.

30. Payo I. et al. Experimental validation of nonlinear dynamic models for single-link very flexible arms // Proc. 44th IEEE Conf. Decis. Control. Eur. Control Conf. Sev. 2005. 6 p.

31. Cocuzza S., Pretto I., Debei S. Novel reaction control techniques for redundant space manipulators: Theory and simulated microgravity tests // Acta 
Astronaut. 2011. Vol. 68, № 11. P. 1712-1721.

32. Ullman M.A., CannonJr R.H., Rock S.M. A modular system architecture for multimanipulator, free-flying spacerobots // Proc. IEEE Int. Symp. Intell. Control. Chicago. 1993. 8 p.

33. Machairas K. et al. Extending the NTUA Space Robot Emulator for Validating Complex On-Orbit Servicing Tasks // Proc. 12th Symp. Adv. Sp. Technol. Robot. Autom. 2013. 7 p.

34. Papadopoulos E. et al. The NTUA Space Robotic Emulator: Design and Experiments // Int. Conf. Intell. Robot. Syst. IROS 11 Work. Sp. Robot. Simul. 2011. $14 \mathrm{p}$.

35. Robertson A., Inalhan G., How J.P. Spacecraft formation flying control design for the Orion mission // Proc. AIAA Guid. Navig. Control Conf. 1999. 14 p.

36. Иванов Д.С., Овчинников М.Ю. Математическое моделирование управляемого движения многоэлементной системы // Препринты ИПМ им. М.В. Келдыша. 2008. № 72. С. 32.

37. Tweddle B.E. Relative computer vision-based navigation for small inspection spacecraft // Proc. AIAA Guid. Navig. Control Conf. 2011. 15 p.

38. Andrade C. et al. Robust Control Applied Towards Rendezvous and Docking // Proc. Eur. Control Conf. 2009. 6 p.

39. Di Mauro G. et al. Experimental Implementation of SDRE Method for Autonomous Rendezvous and Docking Maneuvering // Proc. 5th Int. Conf. Spacecr. Form. Fly. Mission. Technol. 2013. 15 p.

40. Guglieri G. et al. Design and development of guidance navigation and control algorithms for spacecraft rendezvous and docking experimentation // Acta Astronaut. 2014. Vol. 94, № 1. P. 395-408.

41. Curti F., Romano M., Bevilacqua R. Lyapunov-Based Thrusters' Selection for Spacecraft Control: Analysis and Experimentation // J. Guid. Control. Dyn. 2010. Vol. 33, № 4. P. 1143-1160.

42. Chen Y. et al. History of the Tether Concept and Tether Missions: A Review // ISRN Astron. Astrophys. 2013. Vol. 2013. P. 1-7.

43. Nakaya K. et al. On Formation Deployment For Spinning Tethered Formation Flying and Experimental Demonstration // Proc. 18th Int. Symp. Sp. Flight Dyn. 2004. P. 531-536.

44. Gates S.S., Koss S.M., Zedd M.F. Advanced Tether Experiment Deployment Failure. 2001. Vol. 38, № 1. P. 60-68.

45. Uyama $\mathrm{N}$. et al. Impedance-based contact control of a free-flying space robot with a compliant wrist for non-cooperative satellite capture // IEEE Int. Conf. Intell. Robot. Syst. 2012. P. 4477-4482.

46. Zhao Z., Zhao J., Liu H. Development of a landing mechanism for asteroids with soft surface // Int. J. Aerosp. Eng. 2013. Vol. 2013. 9 p. 


\section{Оглавление}

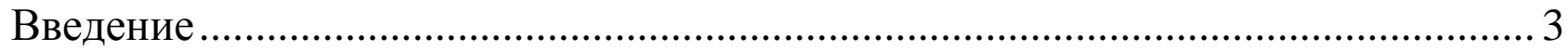

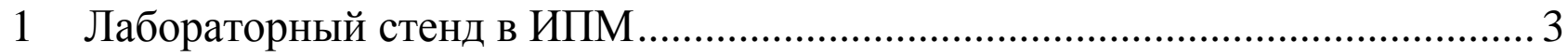

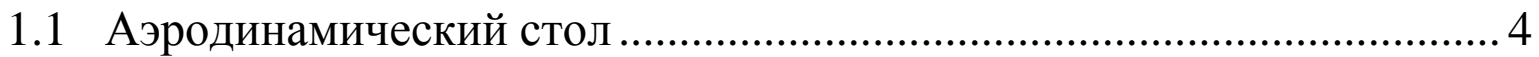

1.2 Промышленный вентилятор …………........................................... 5

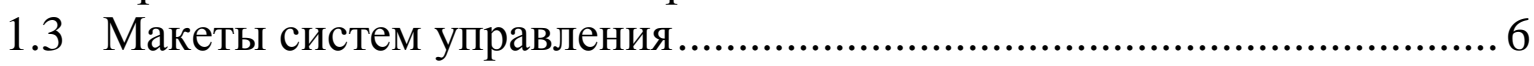

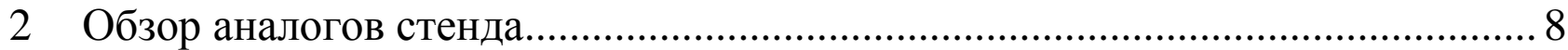

2.1 Возможные реализации аэродинамического стола .............................. 8

Использование автономной воздушной подушки ................................... 8

Аэродинамический стол с воздушной подушкой ................................... 10

2.2 Обзор методов определения движения

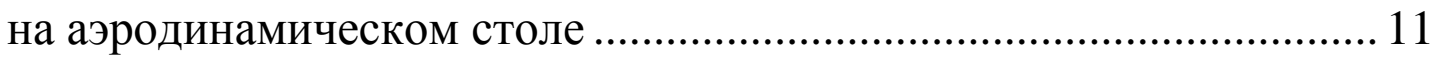

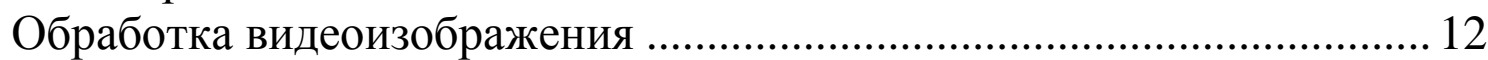

Лазерные дальномеры......................................................................... 19

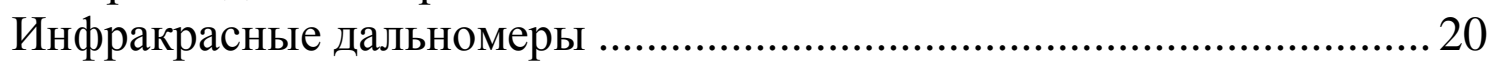

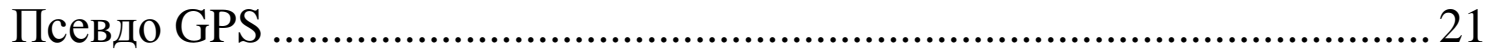

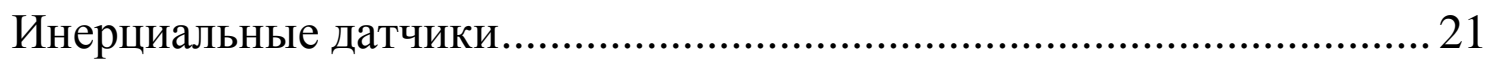

2.3 Обзор задач, решаемый с помощью аэродинамического стола ........22

Тестирование манипуляторов для космических систем.......................22

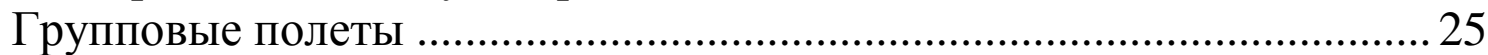

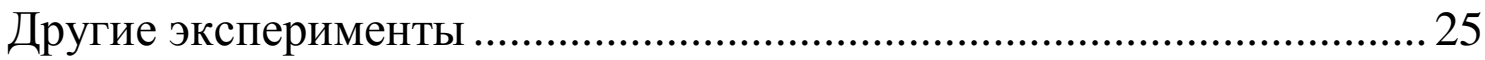

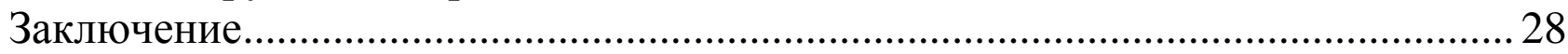

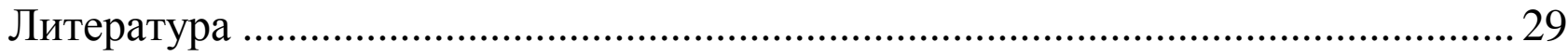

